\title{
Providing new opportunities to adolescent girls in socially conservative settings: The Ishraq program in rural Upper Egypt [Arabic]
}

Martha Brady

Population Council

Ragui Assaad

Population Council

Barbara L. Ibrahim

Abeer Salem

Population Council

Rania Salem

See next page for additional authors

Follow this and additional works at: https://knowledgecommons.popcouncil.org/departments_sbsr-pgy

Part of the Demography, Population, and Ecology Commons, Family, Life Course, and Society Commons, and the International Public Health Commons How does access to this work benefit you? Let us know!

\section{Recommended Citation}

Brady, Martha, Ragui Assaad, Barbara L. Ibrahim, Abeer Salem, Rania Salem, and Nadia Zibani. 2006.

"Providing new opportunities to adolescent girls in socially conservative settings: The Ishraq program in rural Upper Egypt [Arabic]." Cairo: Population Council. 


\section{Authors}

Martha Brady, Ragui Assaad, Barbara L. Ibrahim, Abeer Salem, Rania Salem, and Nadia Zibani 


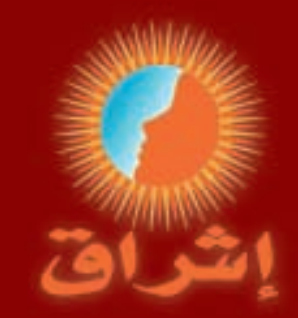

\section{توفير فرص جليلدة للمراهثقات

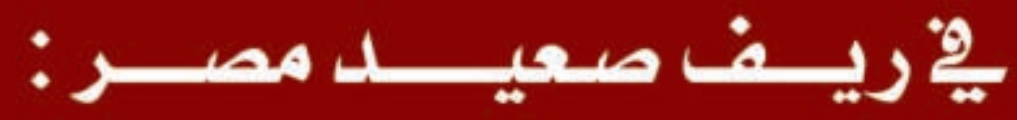

\section{بـرنـاهـــ إثثــراق}

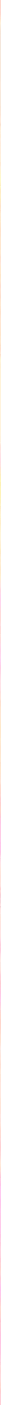

مجلس السـكان الدولى 1 (1) 


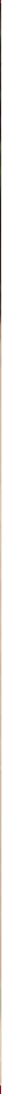

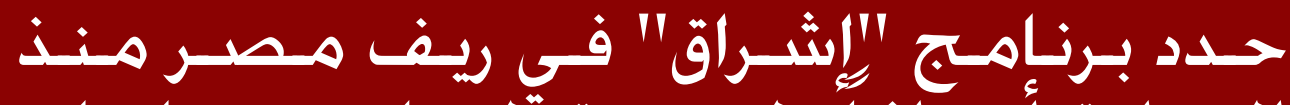

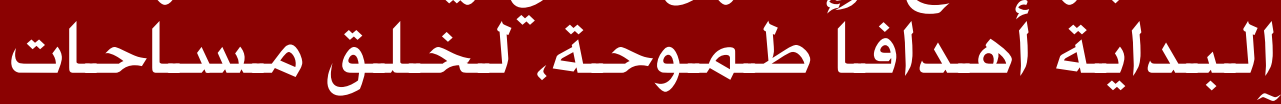

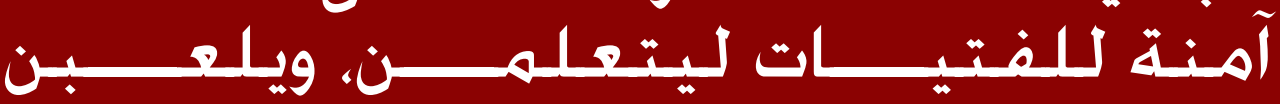

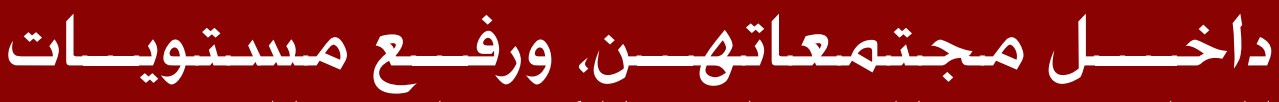

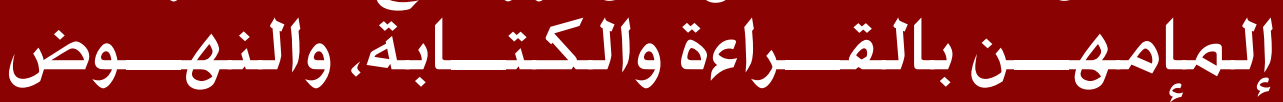

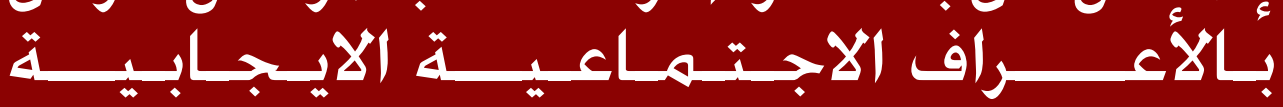

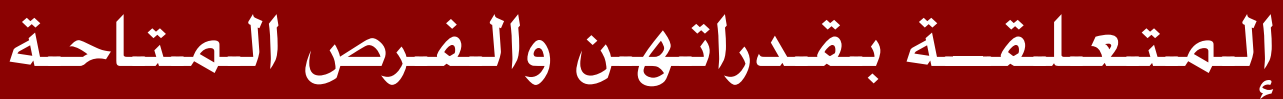
أمامهـن في النحياة. 
في عالم تدفعه العولمة والتكنولوجيا سريعة الوثيرة،

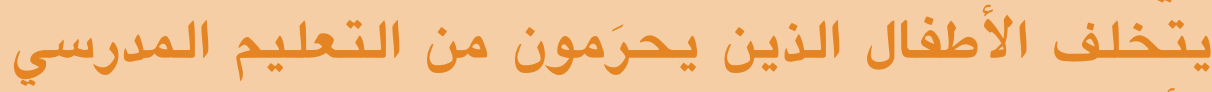

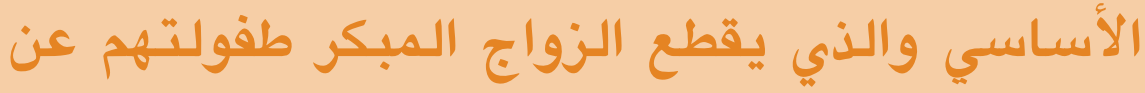

\section{الركب. وهذه هي قصة الفتيات في ريف صعيد هصر.}

فعلى الرغم من التغيرات الكثيرة التى شهدتها مصر على مدار السنوات

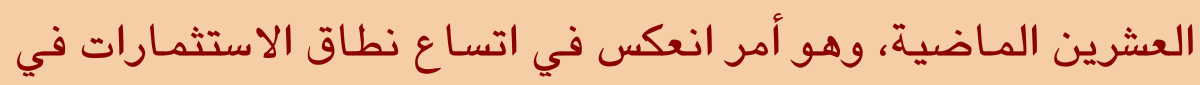
مجال التعليم وارتفاع مستويات الإلمام بالقراءة والكتابة، وتحسن البنية التحتية للمجتمعات الريفية، والنمو النشط في الاقتصاد، وتوسيع نطاق المشاركة في مجال الحياة المدنية، تظل الفتيات في ريف الصعيد

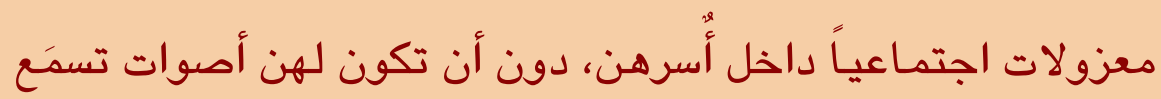
في مجتمعاتهن، وتتحملن عبء الأعمال المنزلية الضخمة، وتخضعن لممارسات تقليدية ضارة كختان الإناث والزواج المبكر. وعلى الرغم من أن جميع الأولاد والبنات في مصر ممن تتراوح أعمارهم بين • إنوات و9 انة (حوالي با ا مليون نسمة) يواجهون تحديات في الوصول الآمن إلى مرحلة النضج، فإن الفتيات في ريف الصعيد هن من

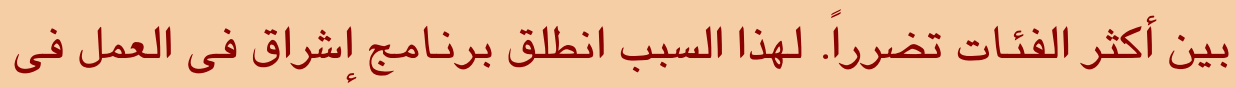

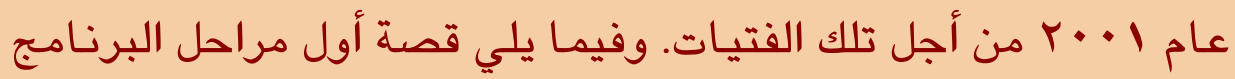
والتغيرات البارزة التي أحدثها في غضون فترة زمنية قصيرة. 
من المعروف أن سنوات الانتقال من الطفولة إلى النضج تجلب في صورتها

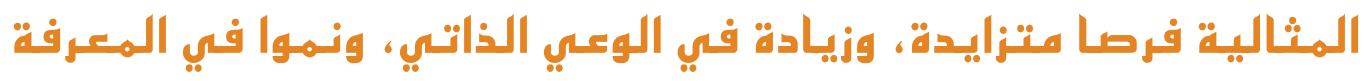

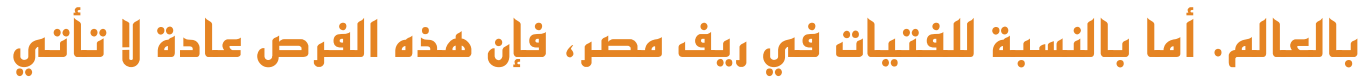
على الإطلالهّ.

بقدر من الموارد والحريـة مقارنة بـأمهاتهن - مؤشرا

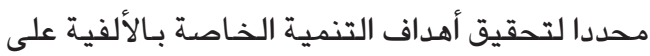

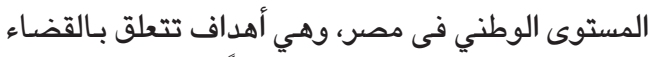

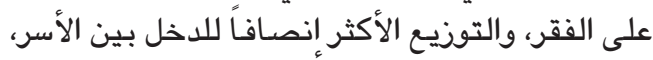

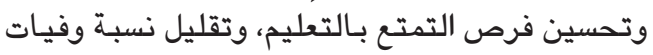

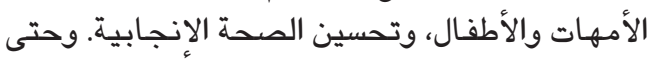

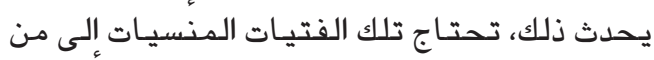

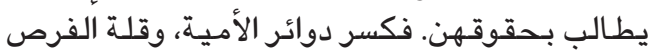

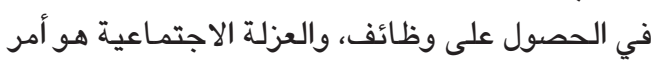

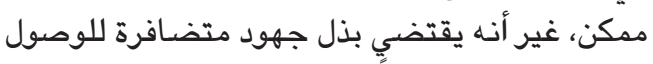

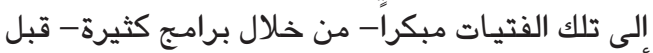
أن يرسخ الزواج والإنجاب المبكر من عزلتهن وفقرهن.

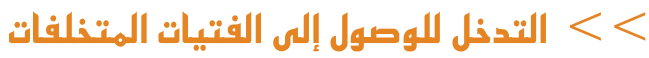

عن الركب كانت تلك الصورة التي ترسم حالة العزلة والهشاشة للفتيات في ريف صعيد مصر هي الحافز وراء خروج ترنج

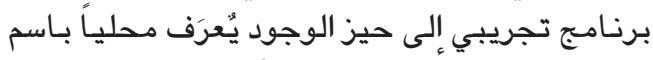

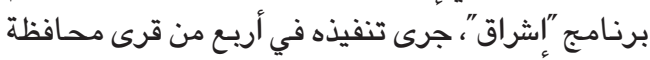

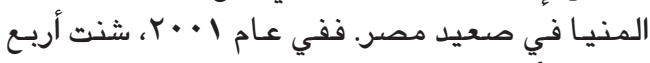

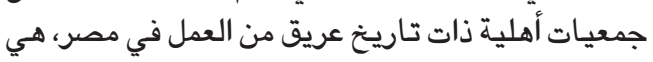

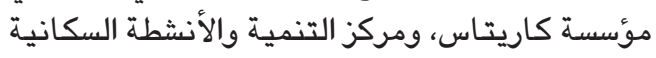

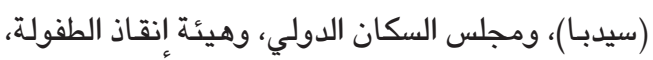

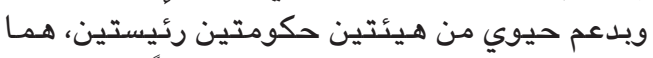

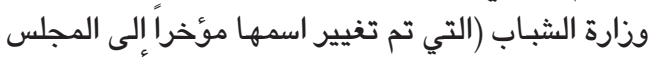

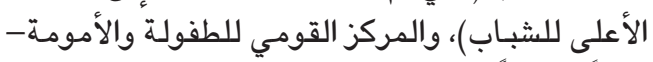

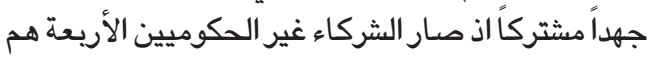

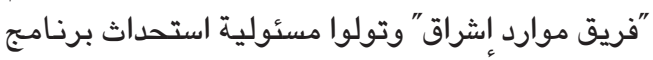

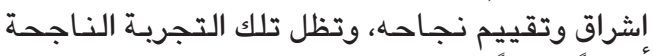

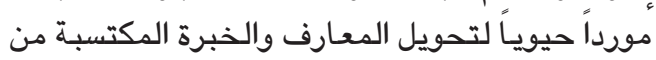
خلال إشراق الى مؤسسات أخرى داخل مصر وخـارجها

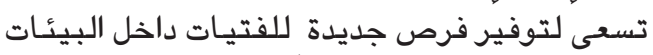
التقليدية والمحافظة اجتماعياً.

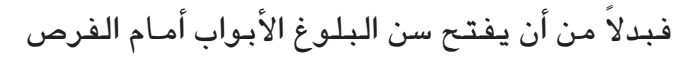

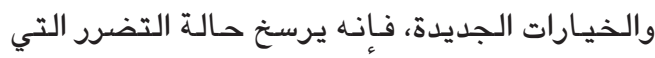

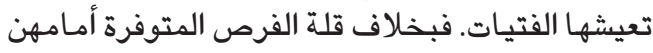
بـالتعليم المدرسي، تتعرض الفتيـات في صعيد مصر

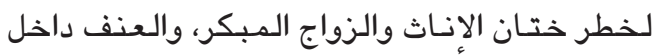

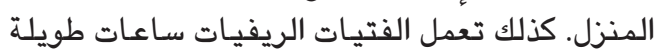

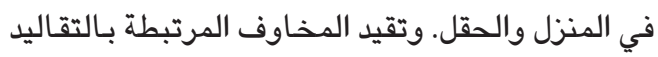
الاجتماعية من حركتهن ومشاركتهن داخل والمتيد المتمع.

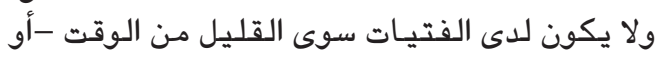

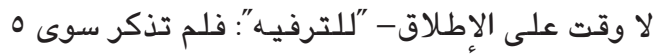

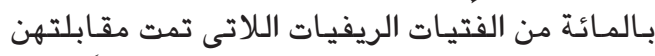

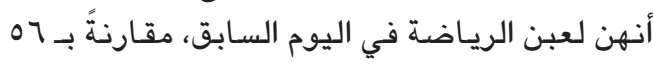

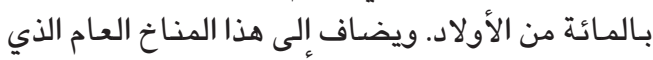

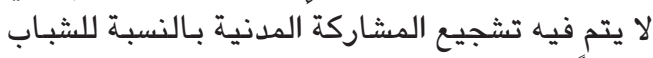

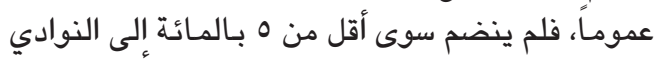

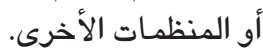

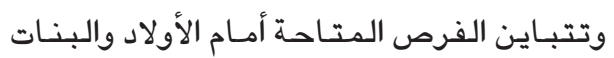

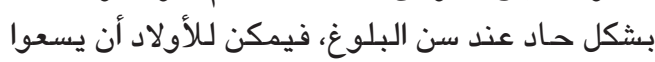

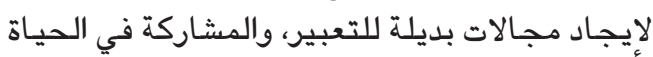

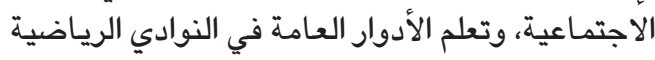

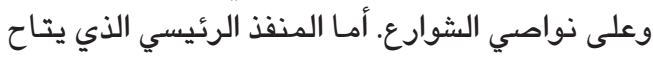
للفتيات كي تتفاعلن خارج إطار الأسرة فيكون المدرسة.

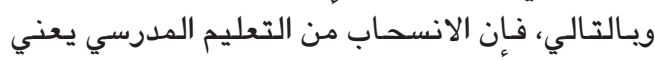

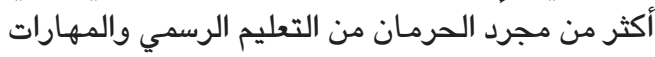

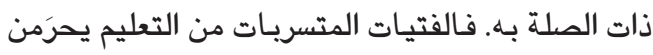

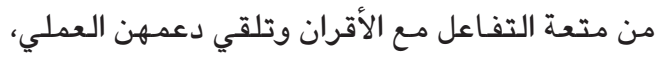

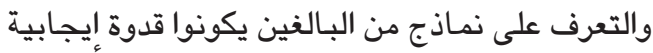

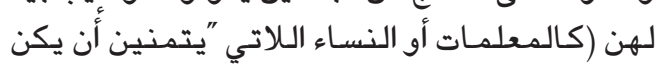

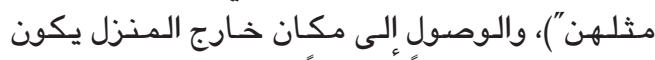

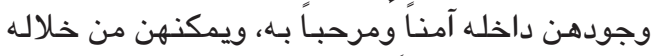
البدء في أن يكن جزءاً من الحياة المجتمعية ومنية.

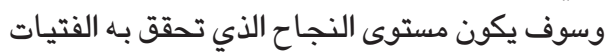

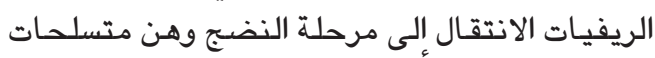


تتمثل الأهداف الرئيسيـة لبـرنـاهـج إشراق في الآتي: - ن الآن

خلق أمـاكن آمنة للفتيـات داخل مجتمعـاتهن وإرساء قواعد المواطنة.

تحسيـن مستويـات إلـمـام الـفتيـات بـالـقراءة

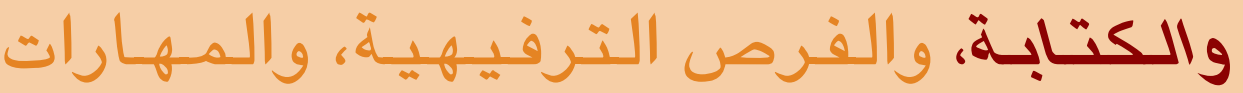

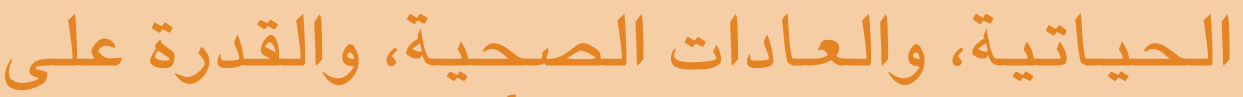

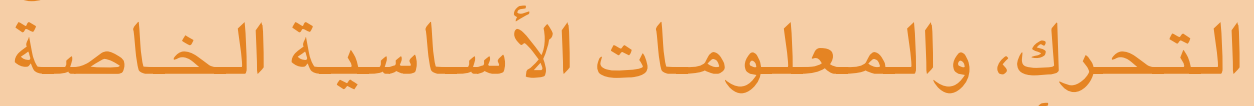

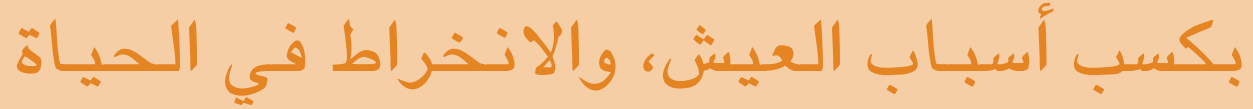

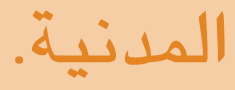

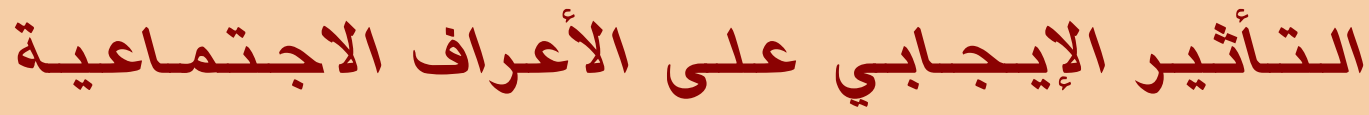

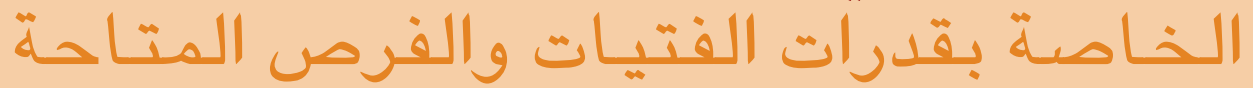
أمامهن في الحياة.

تعزيز ودعم كيانات صنع السيـاسـات المحلية

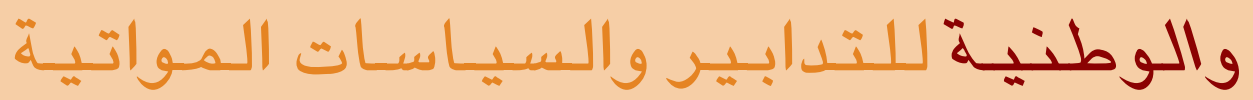

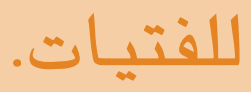



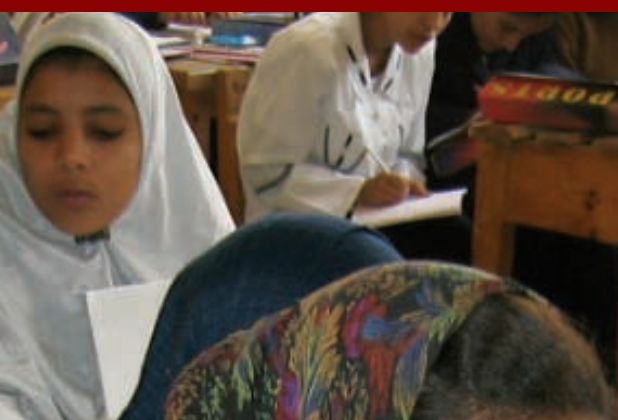

$11 \times 3$

.

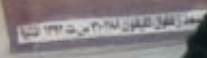
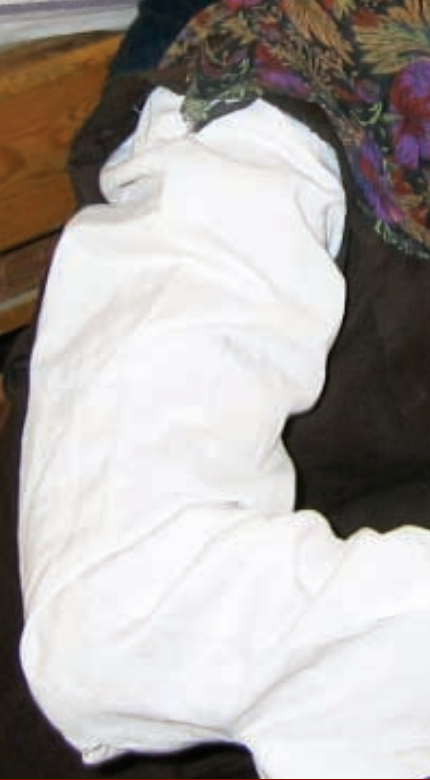

إلب تحسيـين جـوانب الـهياة

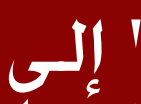

يهـدف "إشـراقي"

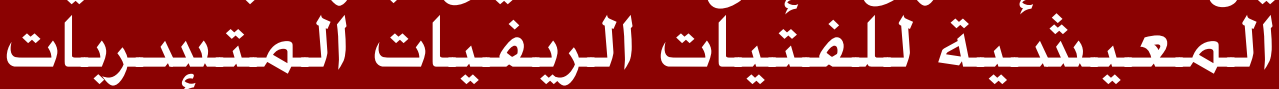

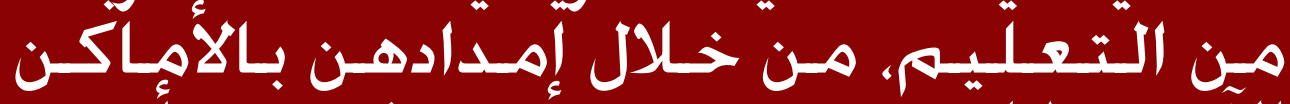

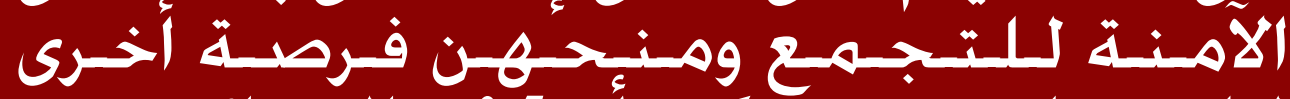

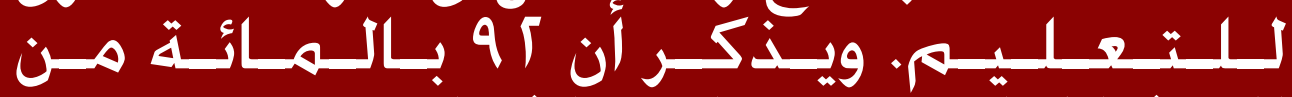

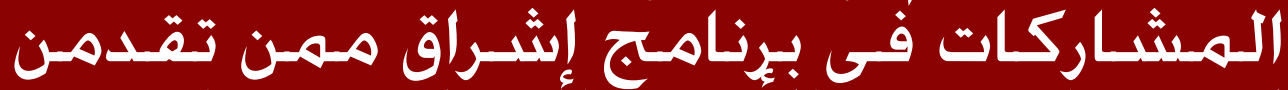

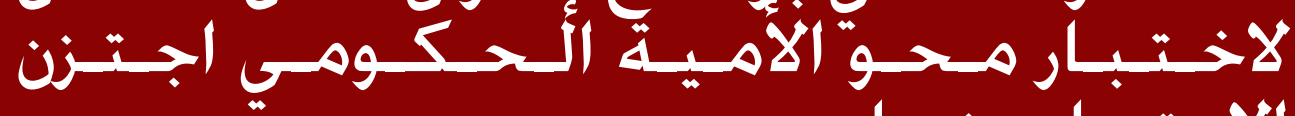
الامتحان بنجاح متحو. 
إليهن. وصـارت المنسقـات فيمـا بعد هـمزة الوصل بين

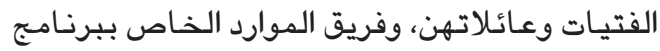

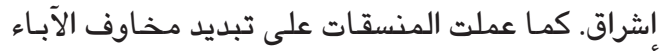

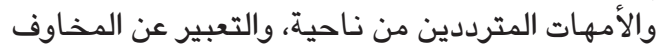

الثقافية للفتيات والتصدي لها من ناحية أخرى.

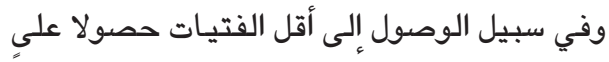

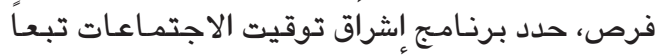

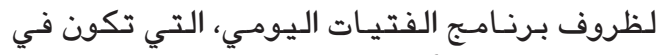

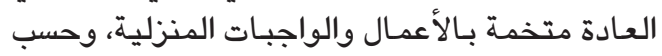

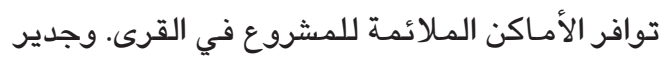

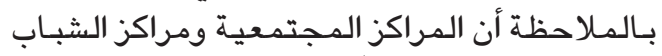

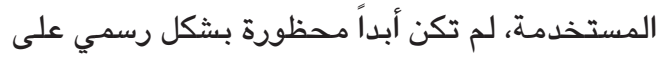

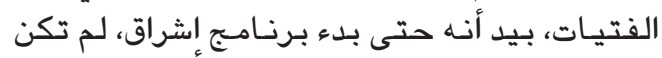

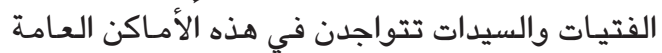
سوى نادرا. كما سعى برنامج إشراق الى تطوير مجموعة من

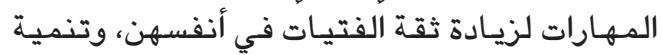

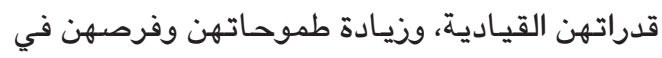

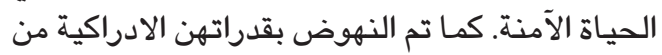
خلال التدريب على اللغة، والحساب، وحل المشكلات.

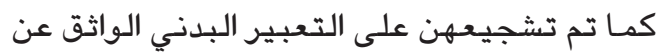

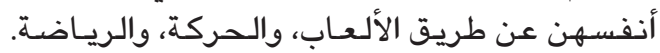

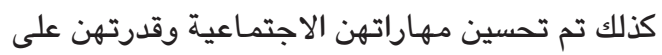

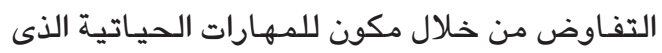

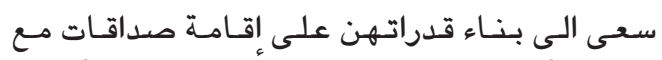

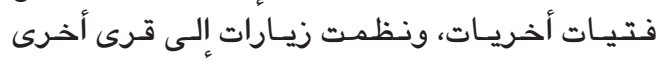

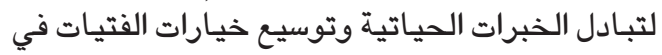
التعلم، وقدمت معلومات صحية دقيقة، وتم تعريفهن

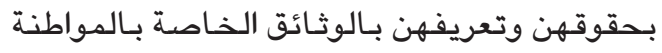
(كشهادات الميلاد ويطاقات الهوية).

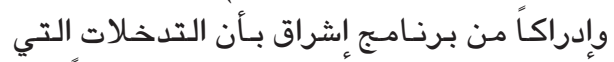

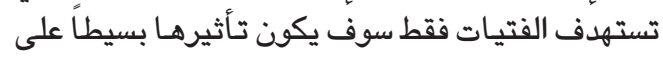

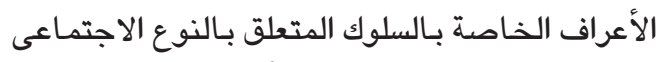

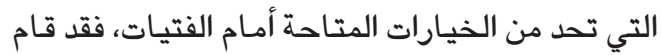

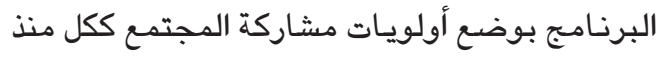
البدايـة. وعمل الفريـق بشكل متزفامن مـع المراهقين

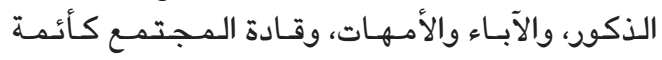

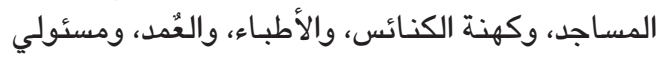

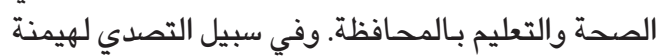

ومن الأهداف الطموحة لبرنامج إشراق، أيضـا تغيير

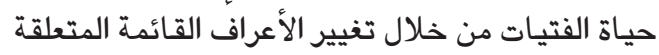

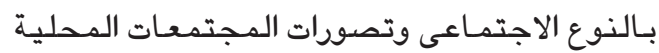

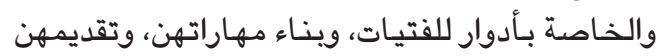

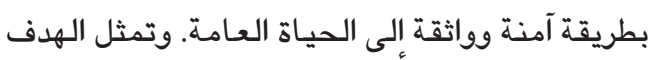

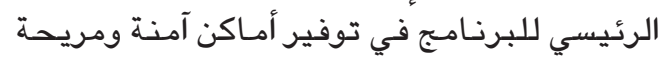

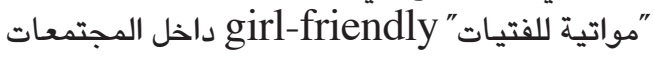

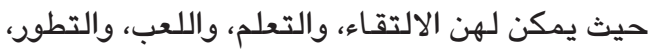

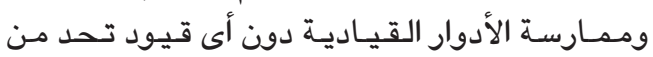
حركتهن.

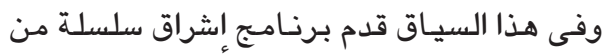
الفرص المتداخلة من فصول محو الأمية، والمهارات

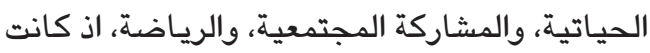

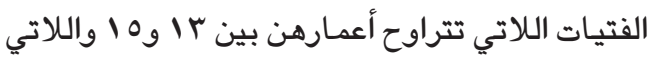

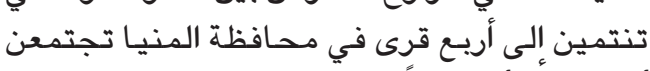

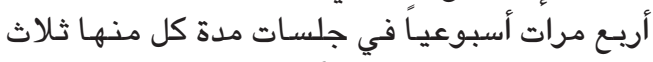

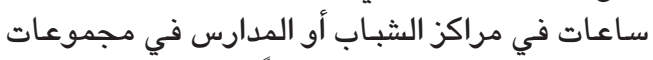

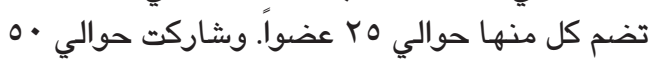
فتـاة من كل قريـة. وفي غضون منه السنة الأولى، تزايد

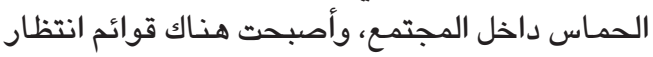
تضم فتيـات ترغبن الاستفـادة من أنشطة البرنـاهج.

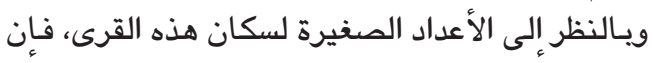

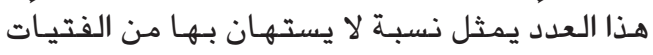

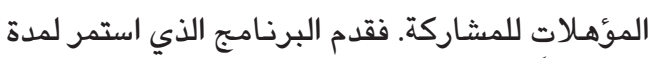

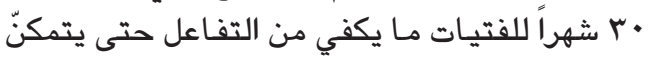

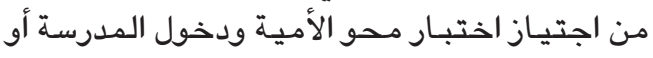

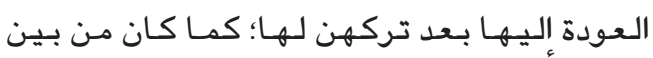

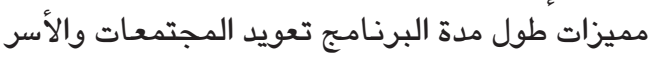

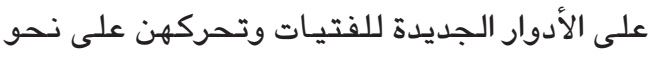

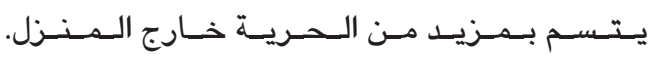

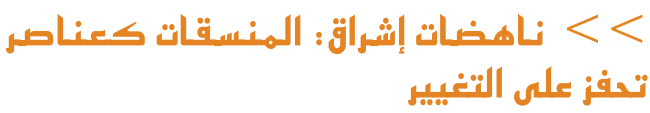
وإدراكاً من فريق الموارد لعدم قدرة الفتيـات المراهقـات

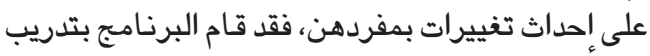

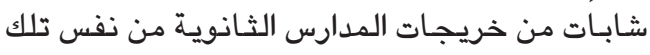

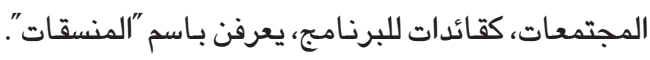

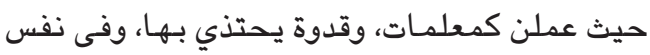

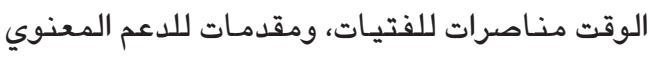




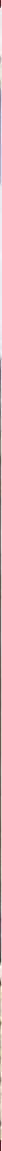

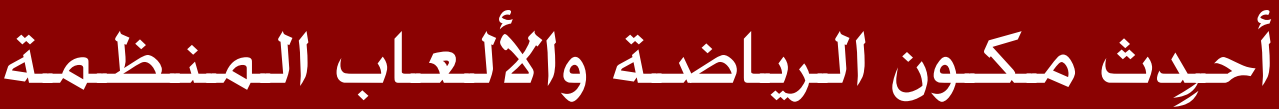

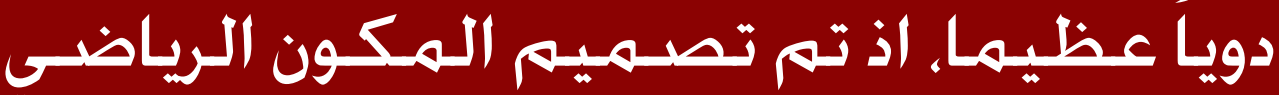

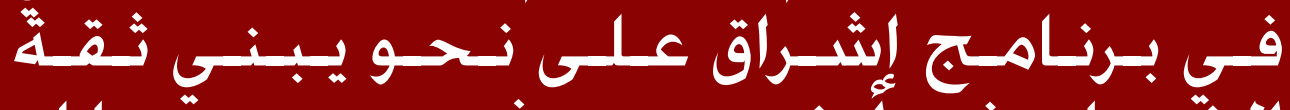

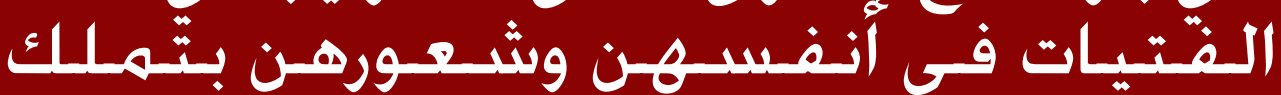

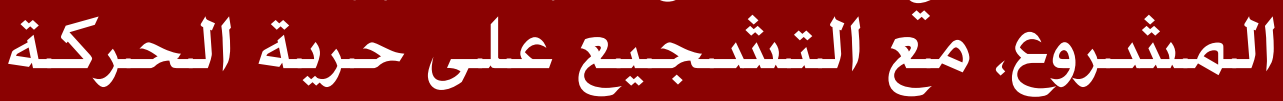

$$
\text { والتعبير البدنى. مغ التئ. }
$$


فبينما تم تفصيل برامج محو الأمية والمهارات الحياتية من مكونات كانت موجودة بـالفعل، فـان المكون

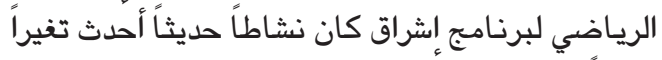

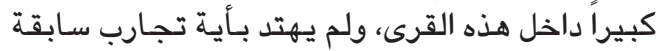

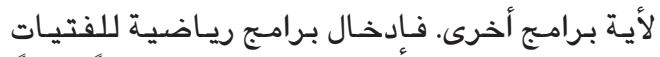

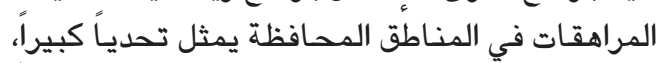

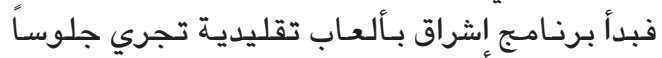

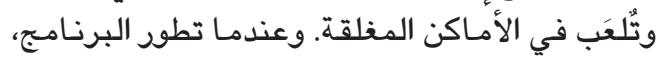

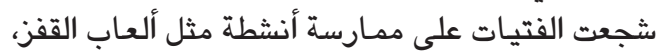

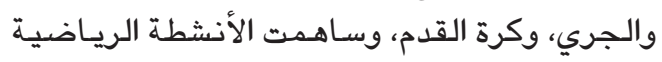
التي مورست فى شعور الفتيـات بمزيد من الارتياح

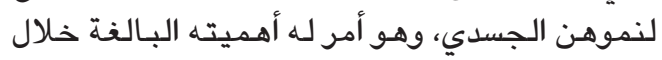

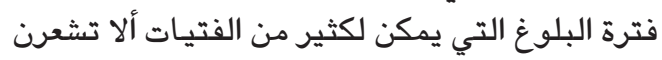

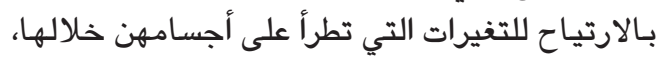

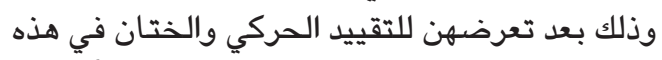

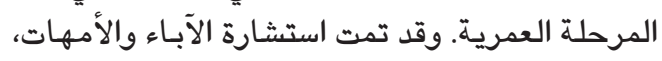
والأشقاء الذكور، وممثلي المجتمع في كافة المراحل

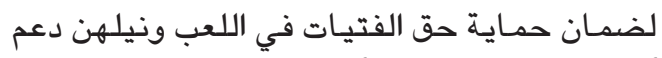

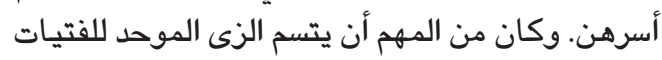

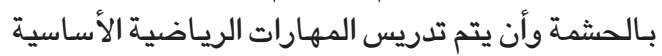

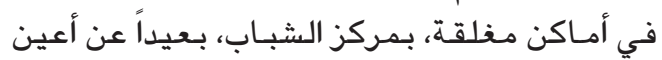
المتطفلين. وثبت أن لعبة تنس الطاولة تناسب جيداً المتطلبات

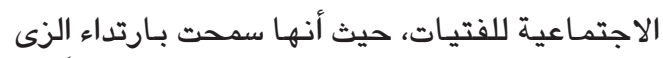

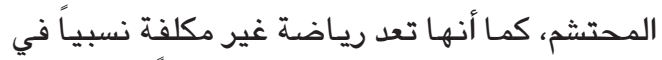

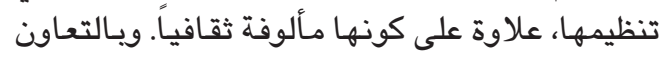

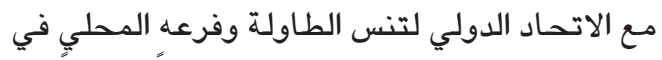

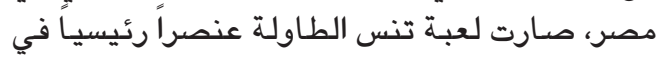

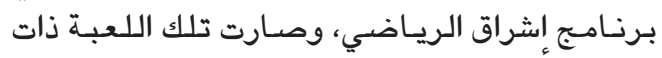

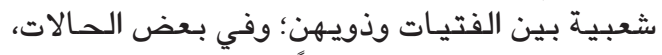

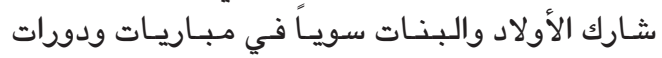

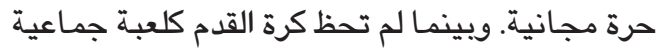

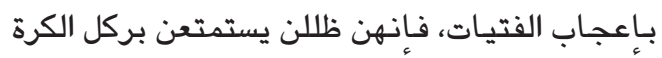
لبعضهن البعض وكان يطيب لهن هذا التمرين النشط.

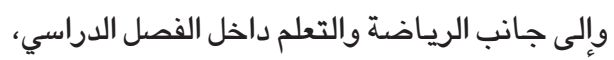

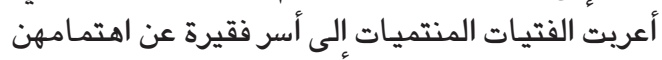

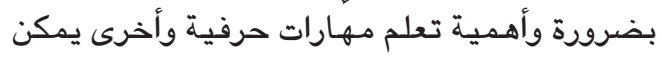

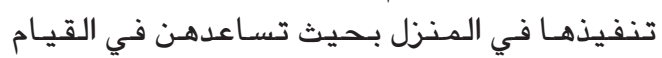
بأدوارهن في المستقبل كأمهات وكمسئولات عن توفير

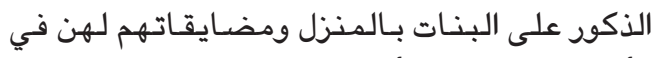

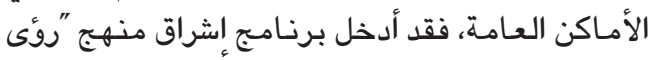

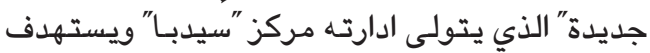

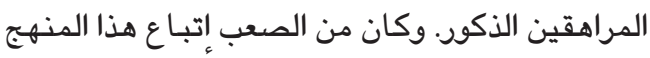

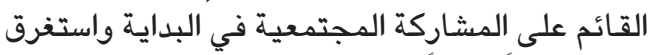
تطويره وقتاً طويلاً - ستة أشهر على الأقل في البداية-

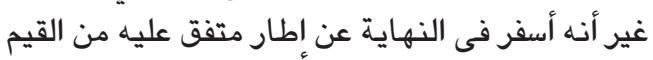
والأهداف تم تنفيذهـا.

\section{>> برنـاهب إشـاقة : عـو الأهيـة، المـهـارات

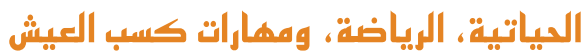
تبنى برنامج إشراق منهج "تعلم تحرر" لمحو الأمية

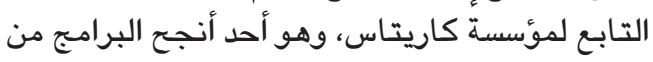

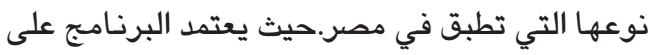
المناقشة النشطة بين المعلمات والفتيات كوسيلة أولى في في

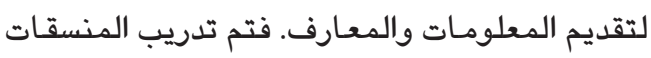

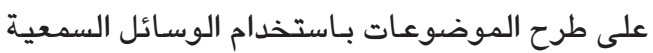
البصرية المصدمة للحفز على التعلم؛ وطلبِ من فتاة

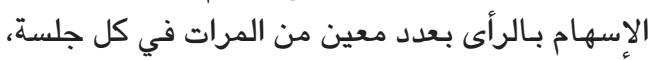

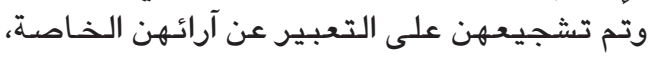
واحترام آراء الآخرين. كانت فصول "تعلم تحرر" تعقَد

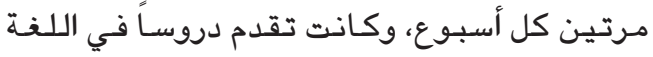

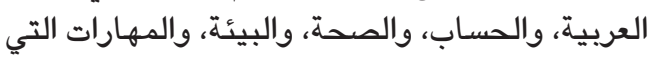

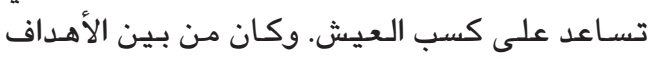

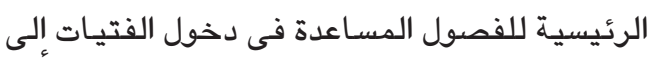

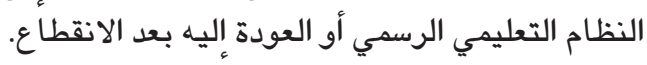

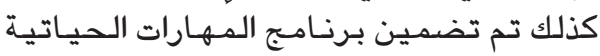
المعروف بـاسم "آنـاق جديدة" والذي ينفزه مركز سيدبـا،

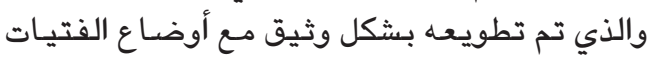

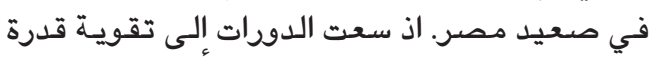
الفتيات على نيل حقوقهن الاجتماعية والانجـابية-

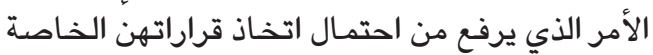

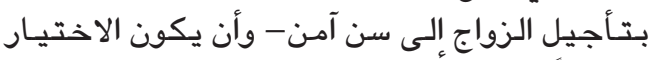

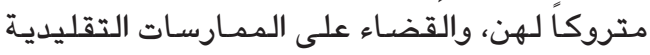

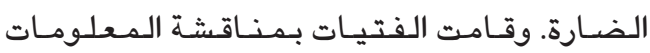

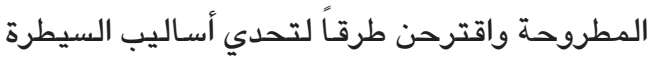

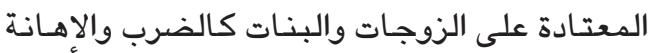

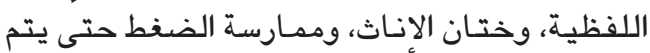
تزويجهن مبكراً. 
الملاحظة التي تفيد بـأن الفتيـات ينقصهن وجود مكان

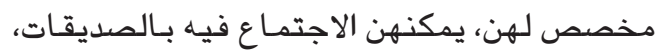

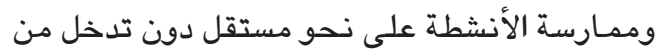

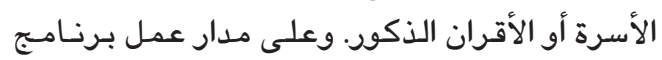

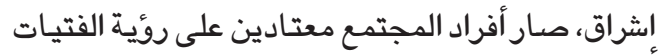

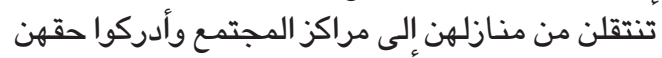

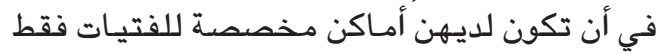

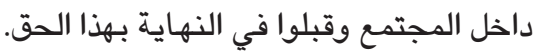

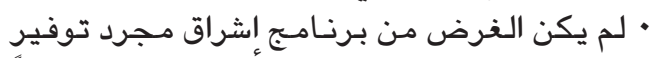
مهارات القراءة والكتـابـة للفتيـات فقط، وإنمـا أيضـاً تسهيل عودتهن إلى التعليم الرسمي أو نظام التعليم الحكومي. • اثنـان وتسعون بـالمائة من المشـاركات ببرنـامج

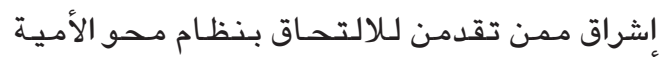

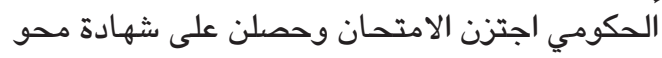

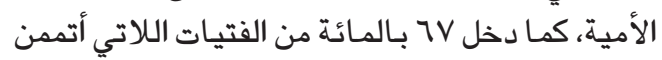

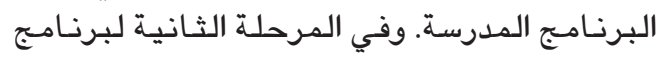

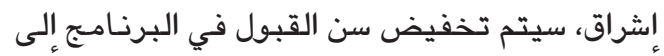

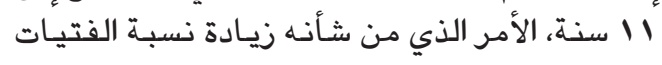

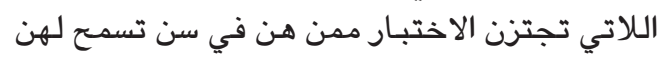
بدخول المدرسة الثانوية.

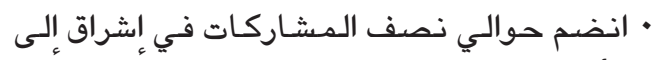

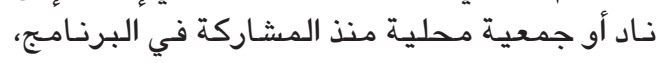

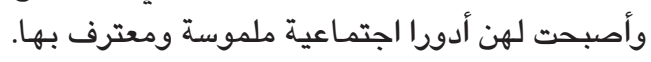

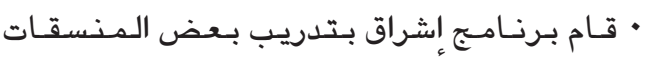

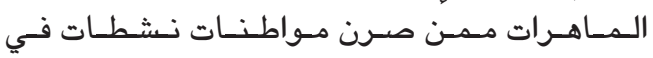

مجتمعاتهن.

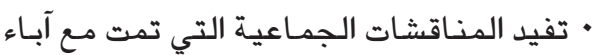

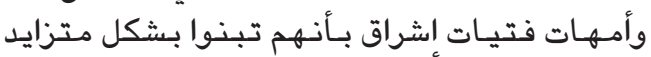

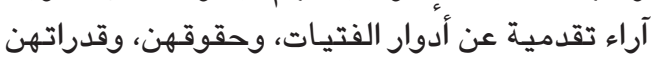
والفرص المتاحة أمامهن.

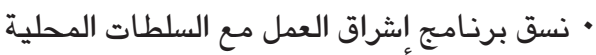

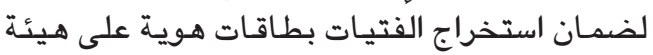
شهادات صحية أو شهادات ميلاد- وهي خطوة أولى الفيـ

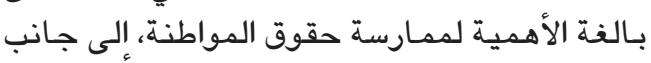

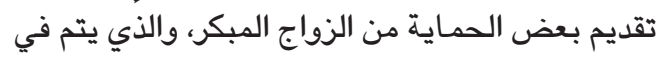
المعتاد تبريره بعدم معرفة السن الحقيقي للفتاة.

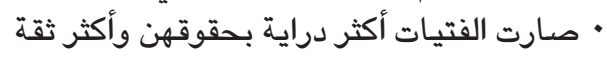
في قدرتهن على ترسيخها وحمايتها. وعقب اكمال
الدخل لأسرهن المعيشية. وكانت الفتيـات حريصـات

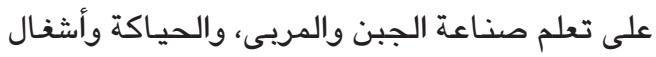

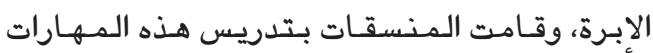

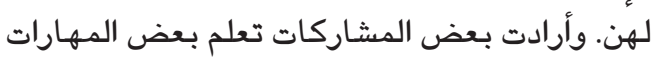

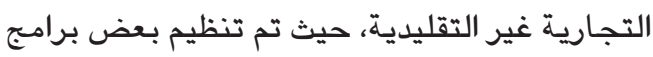
التدريب الحرفي للفتيات الراغبات في ذلك مثل تعلم

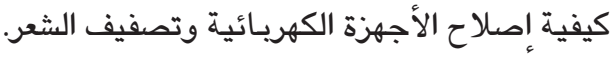

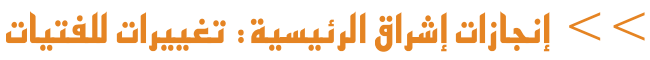

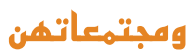

على مدار الشهور الثلاثين الأولى من عمل بـرنـامـج

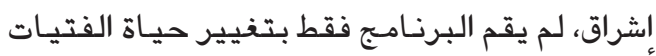
فحسب، وإنما بفضل شمول البرنامج والزيادة النسبية

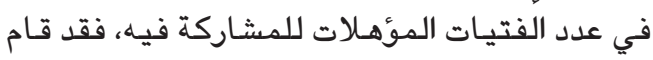

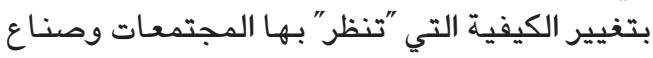
السيـاسـات في صعيد مصر اللى الفتيـات في تلك المرحلة العمرية. وقد تم تقييم برناهج إشراق على نحو صارم عن طريق

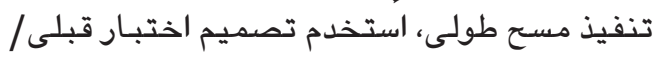

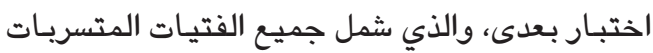

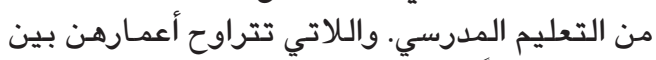

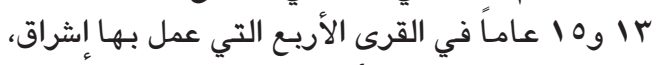

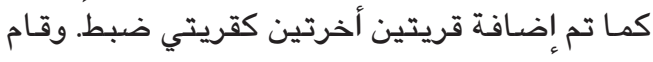

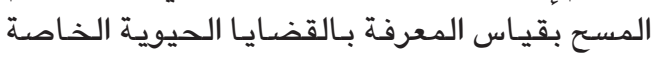

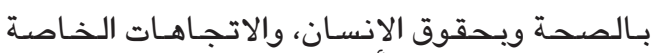

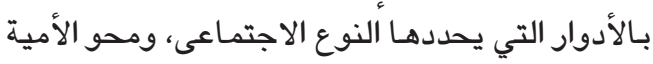

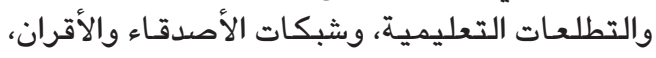

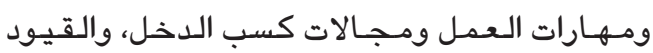

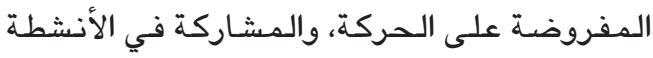

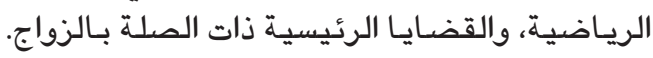

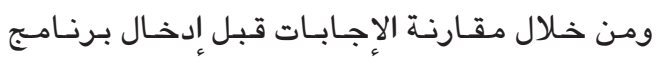

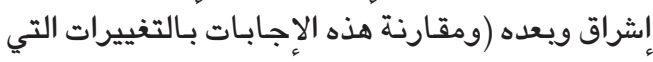

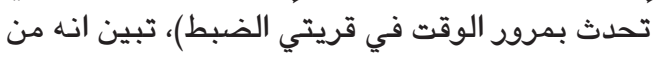

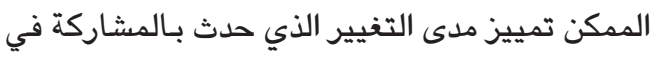
برنامج إشراق. وفيما يلي بعض مدي المؤشرات:

الـمؤشرات الدالة على حدوث تخير في حيـاة

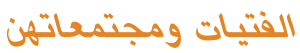
• في البداية، كان مفهوم توفير "أماكن آمنة" يقوم على 


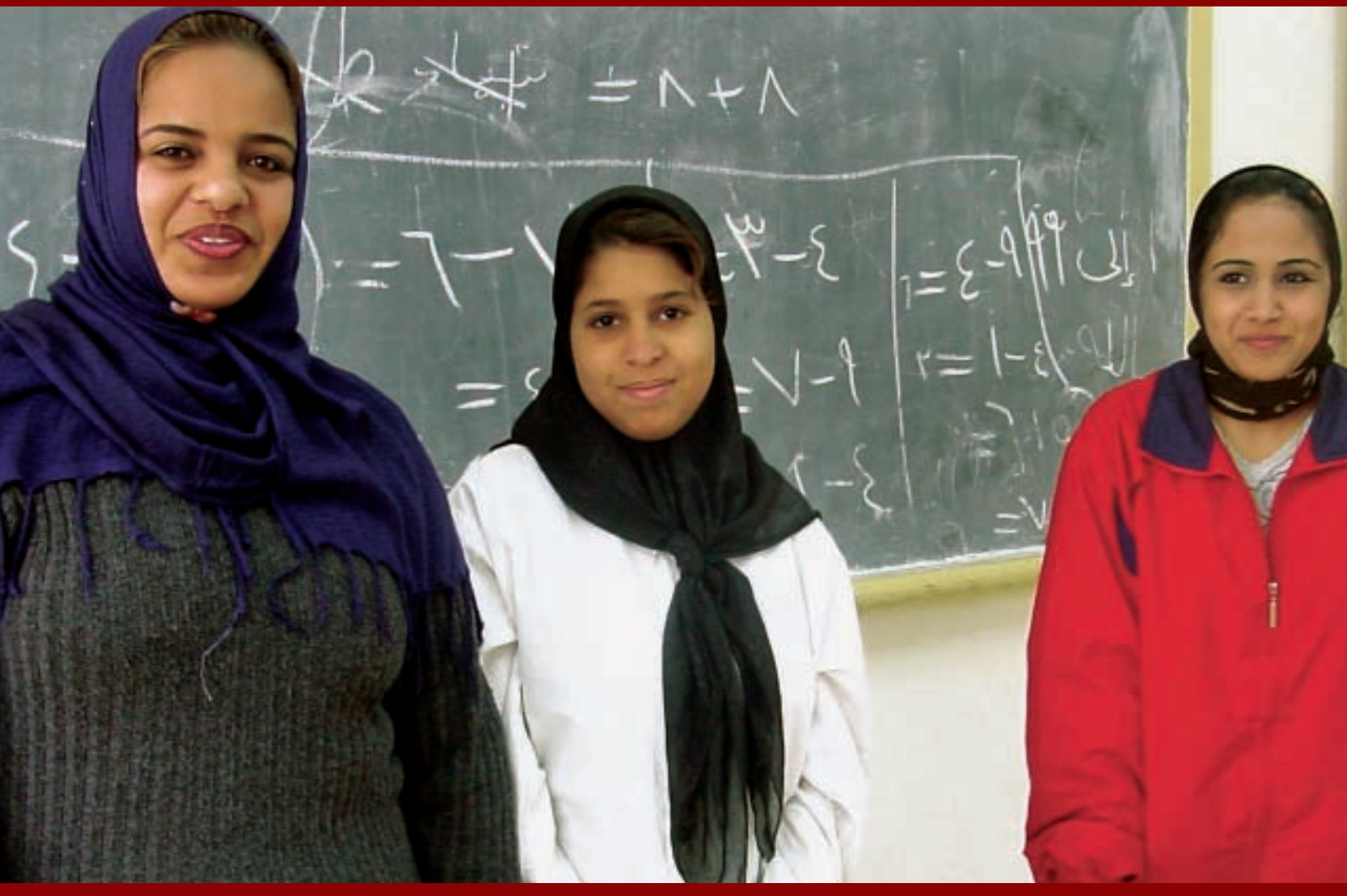

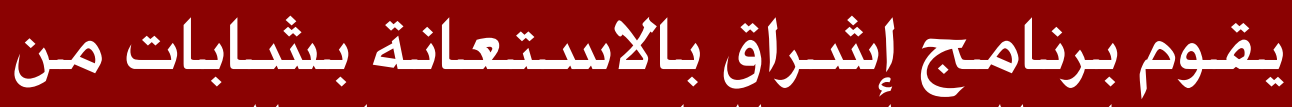

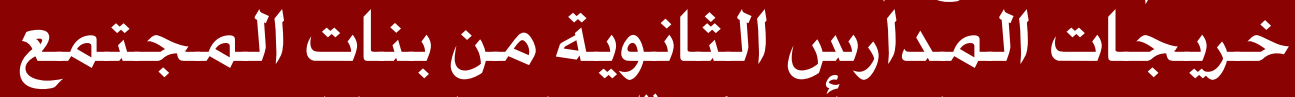

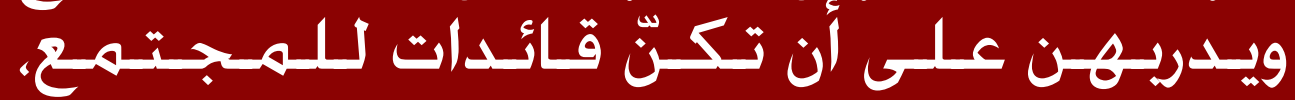

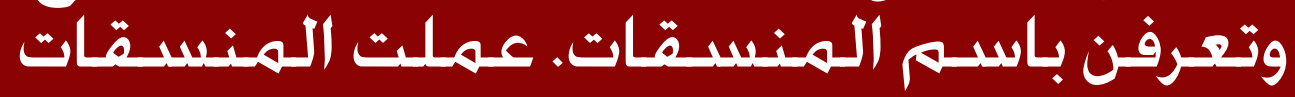

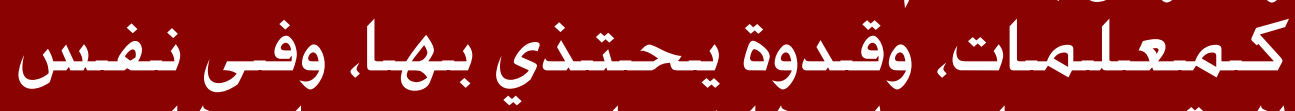

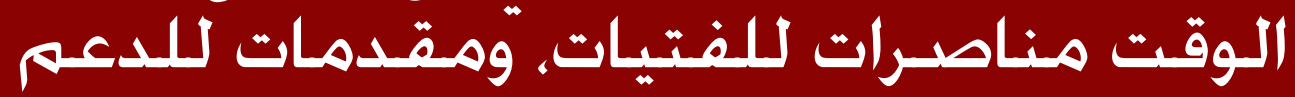

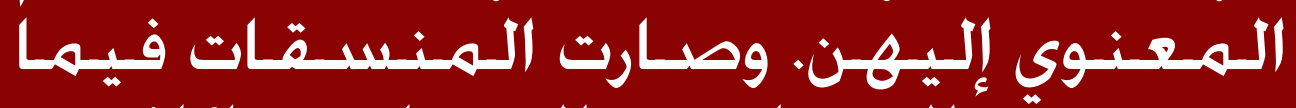

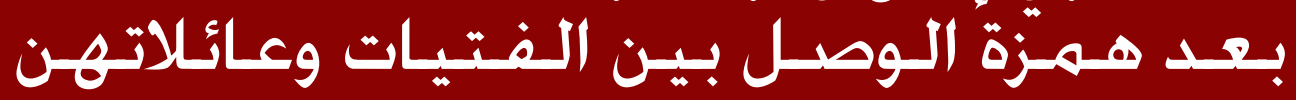
وفريق هوارد إشـراق. 


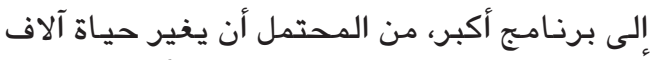

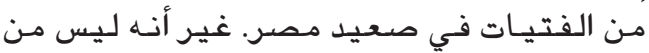

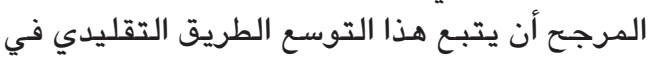

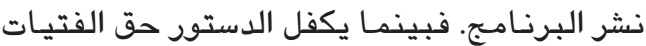

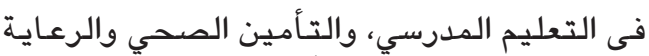

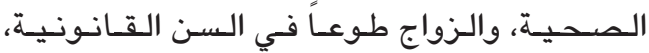

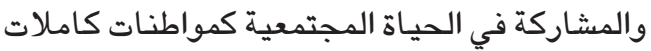

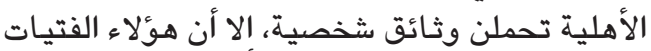

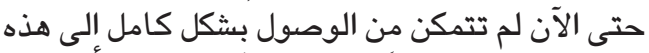

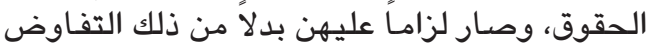

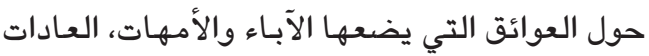

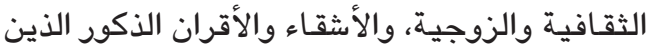

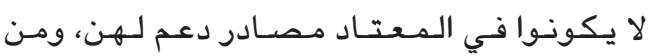

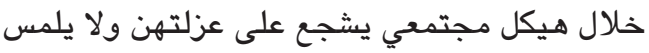

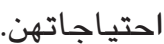
بيّن برنامج إشراق إمكانية حدوث التغيير بل والرغبة

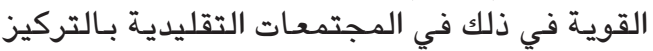

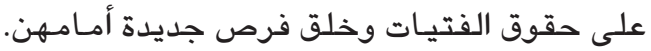

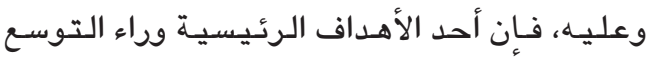

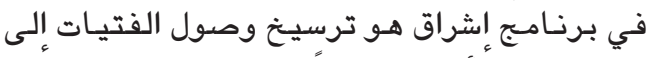

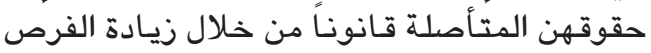

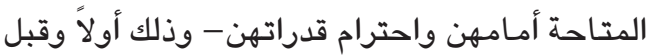

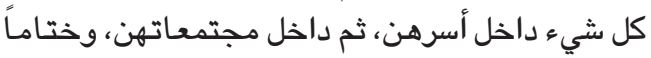

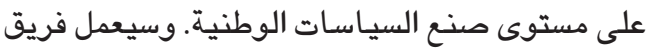

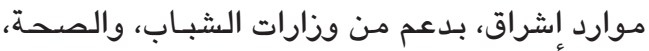

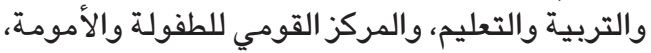

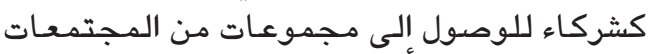

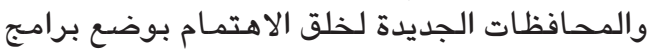

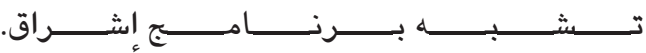

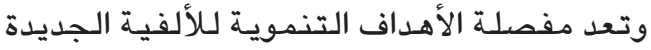

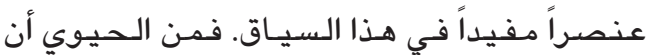

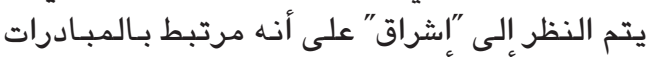

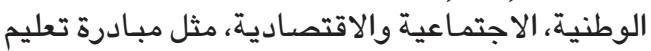

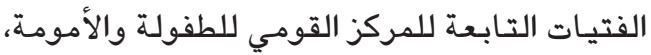

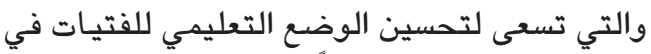

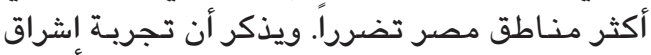

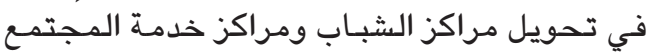
لتضم أماكن خاصة للفتيات والنساء كانت بمثابة الفيا

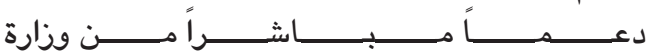

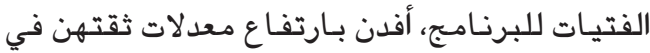

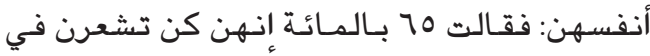
المعتاد "بالقوة والقدرة على مواجهة أية مشكلة".

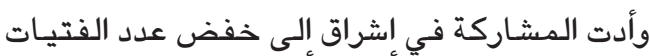

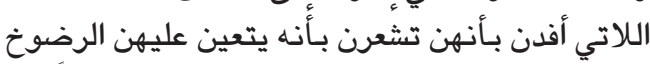

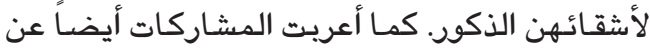

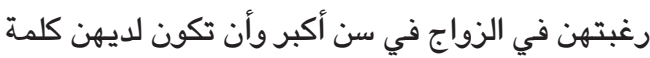

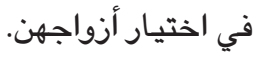
• قام برنامج إشراق بخفض مستوى دعم الفتيات

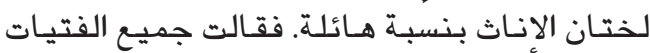

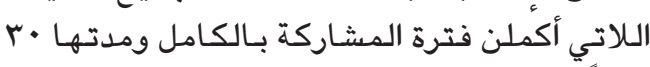

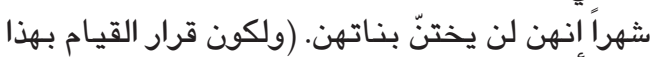

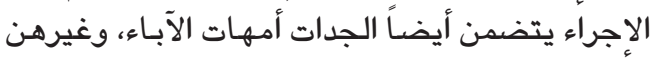

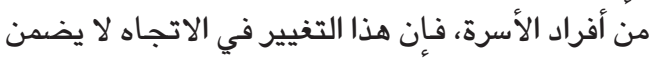

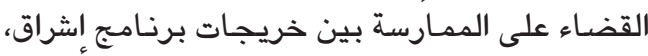

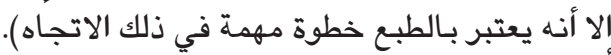

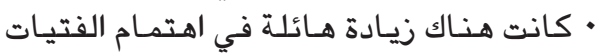

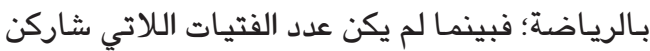

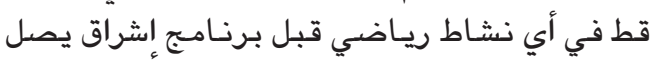

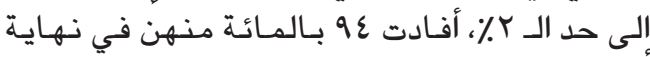

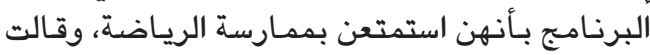

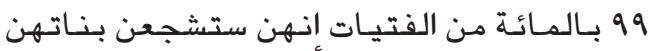

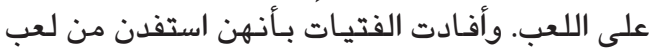

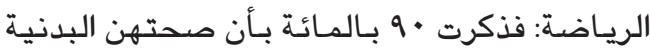

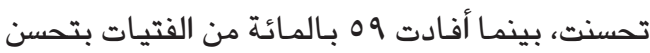
صحتهن العقلية.

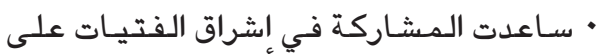

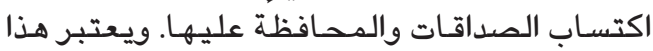

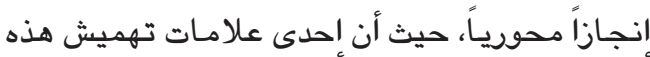

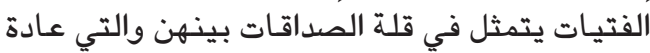

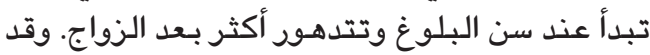

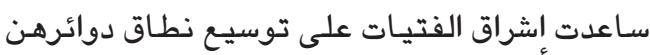

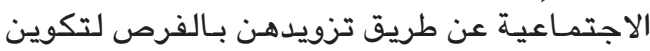

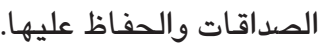

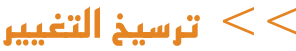

وصل برنـامج "اشراق" الى المرحلة التى تسمح

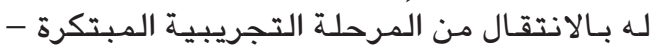

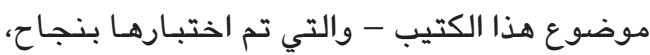




\section{تقييم الفتيات بكلماتهن}

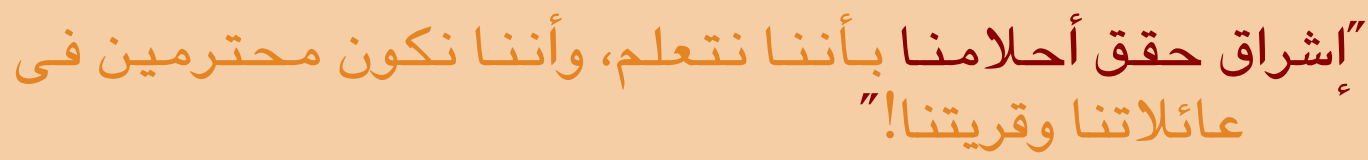

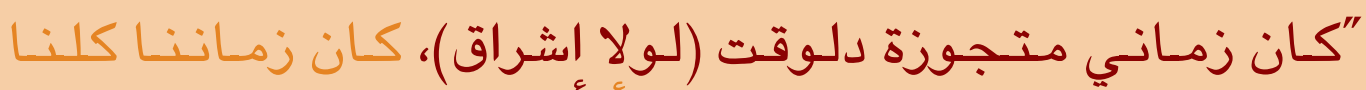

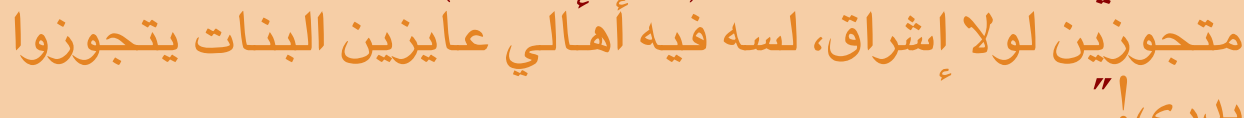

$$
\text { بدري! }
$$

"أول مرة في حياتي أعرف أن البنات ليهم حقوق متساوية في

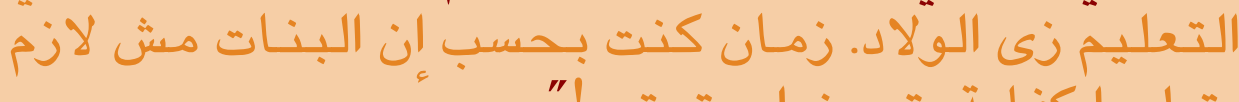

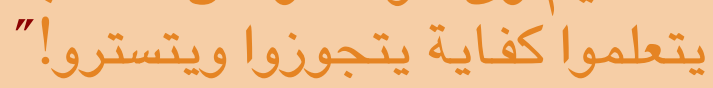

"دلوقت بقي عندي نشاط وحاسة إن صحتي كويسه، الرياضـة

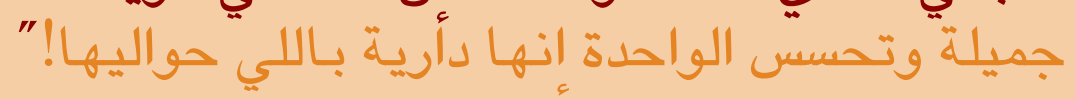

"كنت بـآخذ كل فصل دراسي بجد. يعني الفصل مـاكانش عبارة

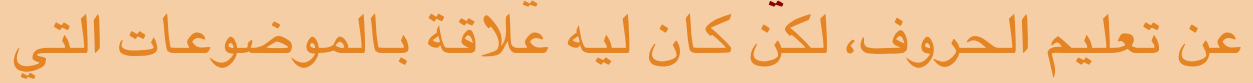

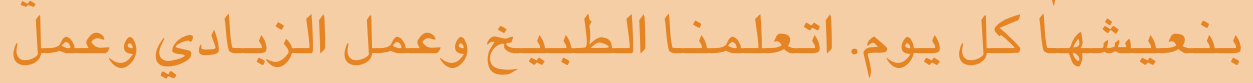

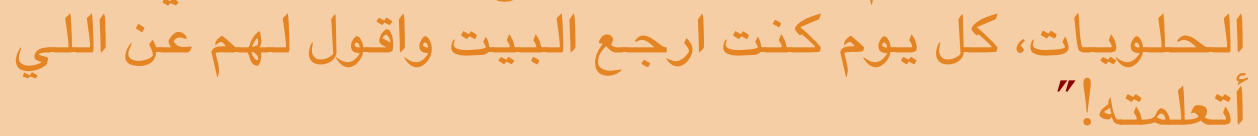

"كنت مسافرة مع أبويـا رايحين أسيوط. وكانت لده أول مرة اخرج

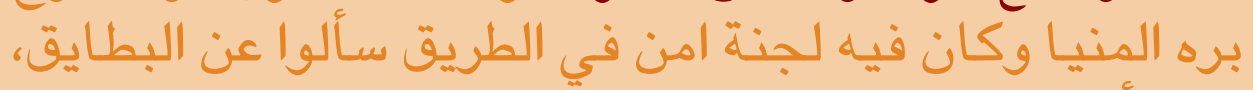

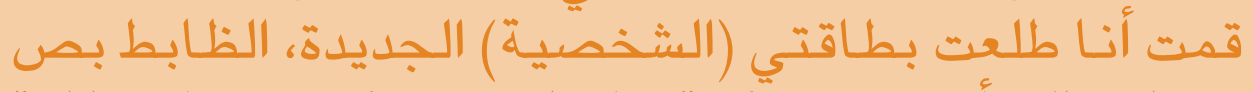

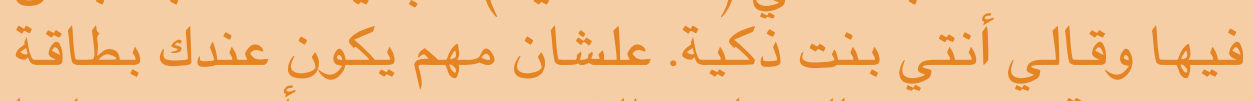

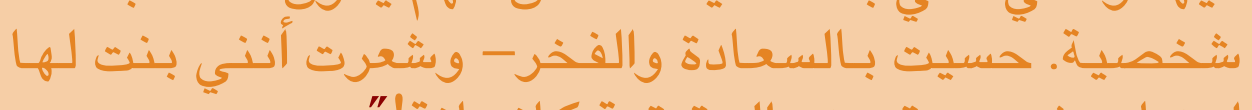
اعتبار، شعرت بقيمتي الحقيقية كانسانة ! 
حساجة لبذل جهود كبيرة ومتواصلـة للاحتفـاظ

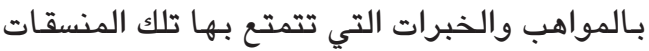
حتى بعد زواجهن وإنجابهن للأطفال.

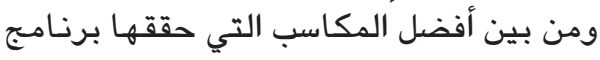

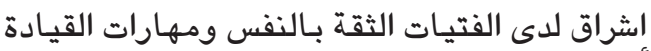

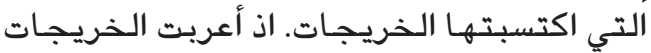

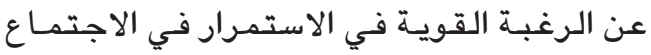

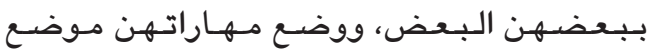

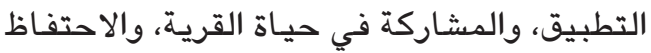

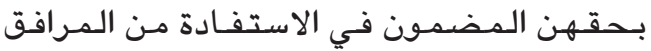
الشبابية والمجتمعية بـالنسبة للأنشطة الجماعية الاعية.

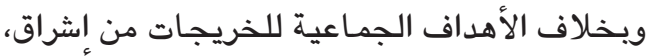

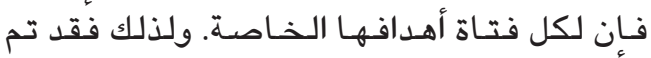

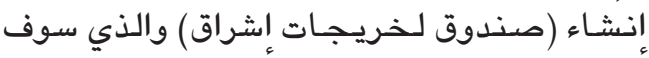

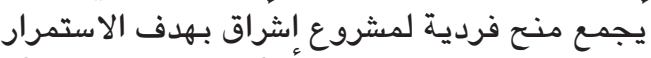

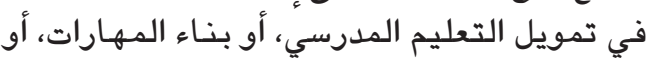

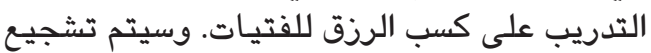

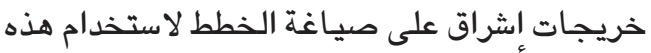
الأموال نحو المزيد من التنمية، ومن ثم الإسهام في معرفتهن بالشئون المالية.

\section{> > المحطات الرئيسية لقياس النباج في

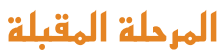

مهد برنـامج إشراق بـالفعل السبيل أمـام التفيير في

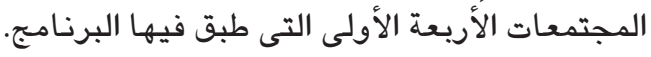
وتم التنظيم لتطبيق البرنامج فى عشر قرى جديدة.

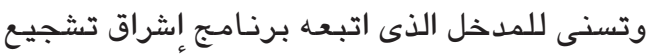

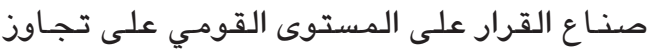

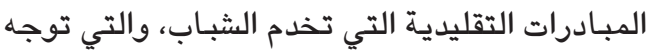
عادة جهودهـا لمستفيدين من الشبـاب الذكور الأكبر

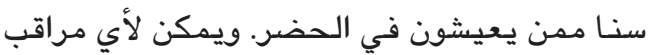

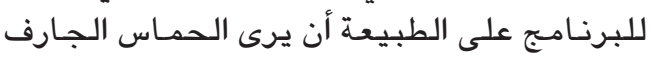

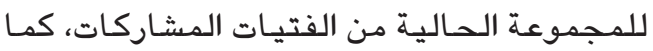

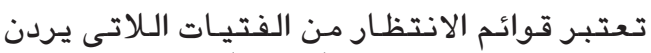

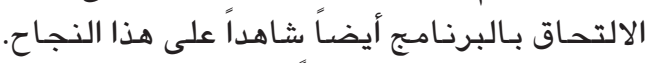

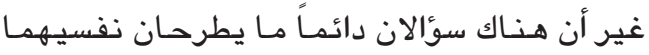

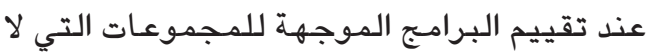

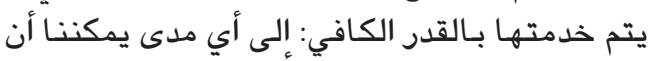

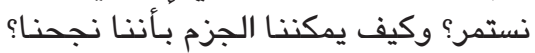

الشباب، حيث أنها تسعى لتحسين مشاركة الفتيات

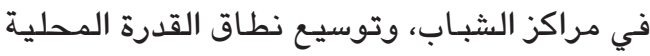
على التنمية على المستوى الشعبي، وتحويلِ مراكز

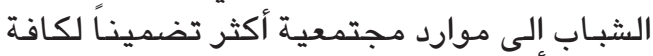

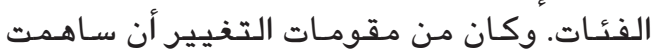

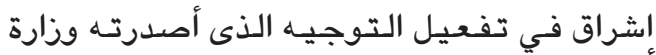

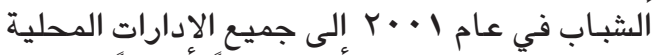

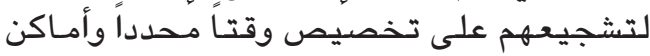

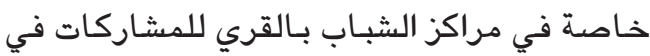
برنامج إشراق وغيرهن من الشـابـات.

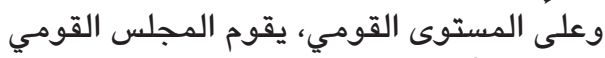

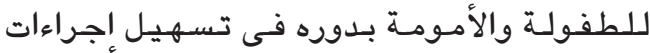

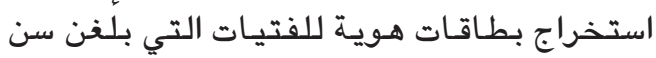
الـ 7 ا، وشهـادات ميلاد للفتيـات اللاتي لم يتم فئم تسجيلهن قط عند مولدهن. وخلال المرحلة الثانية

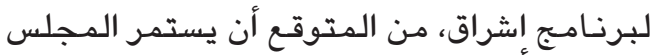

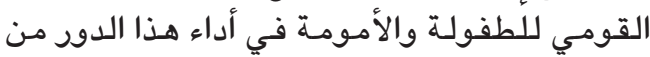

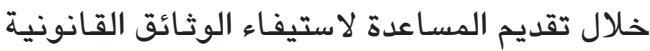

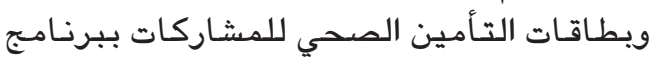

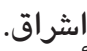
ومن بين أوجـه النجـاح الأسـاسية في المرحلة

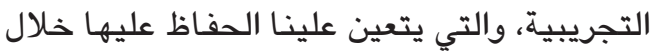

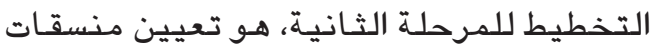

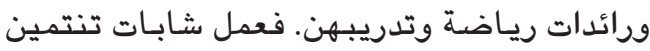

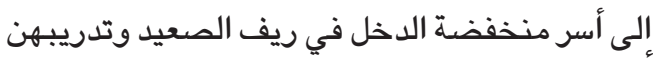
حتى يصبحن معلمات، ومرشدات، ومدرات للدخل في رئل

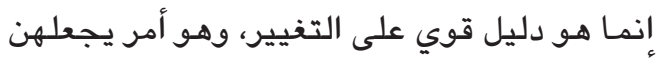

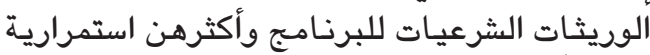
وتأثيراً بعد الخريجات أنفسهن. فقد تحملن مسئولية

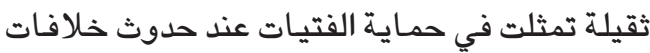
مع الأسر والمجتمعات. وكان الاحترام الذي تطور

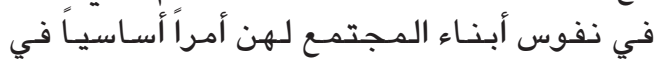
ضمان امكانية قدرة الفتيات على المشاركة.

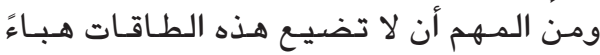

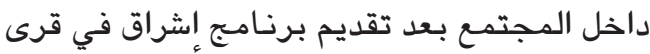

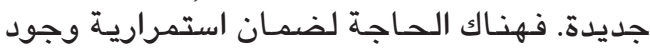

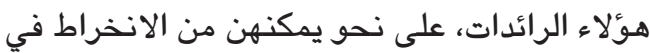

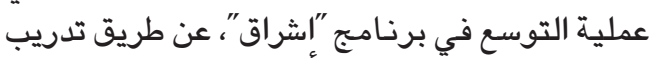

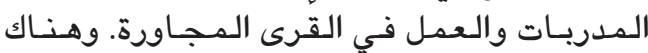




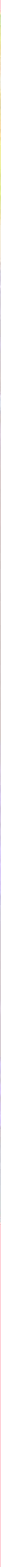




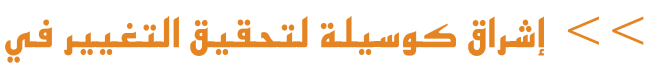

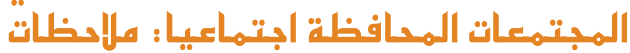

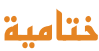

في غياب التدخل التنهوي يكون قََرَ الفتيات الفقيرات، الريفيات، الغير متعلمات في المجتمعات ذات التهن الأعراف

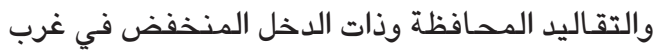

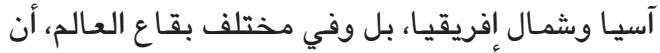

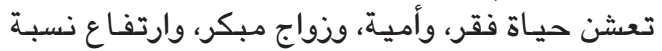

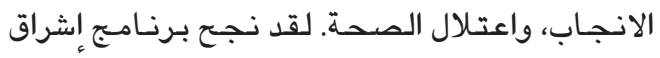

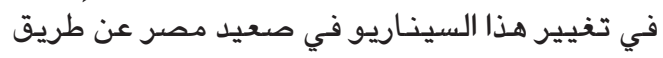

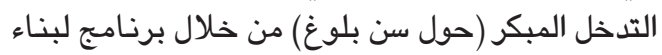

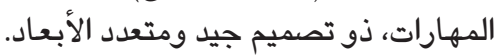

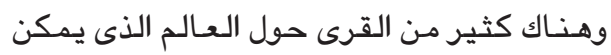

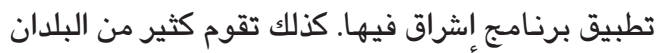

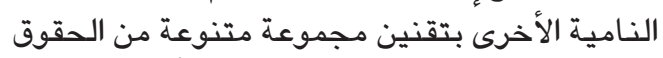

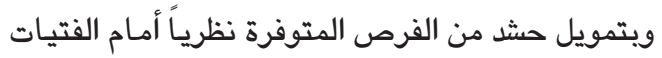

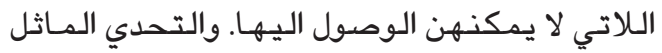

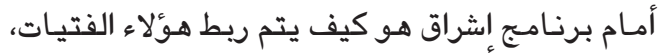

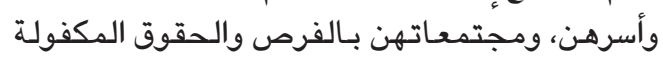

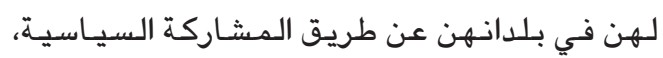

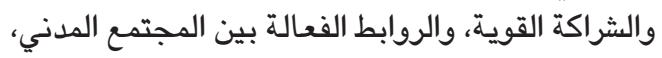
والحكومات المحلية والوطنية، والجمعيات الأهلية.

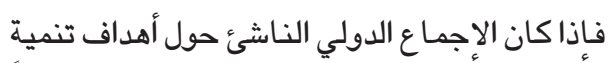

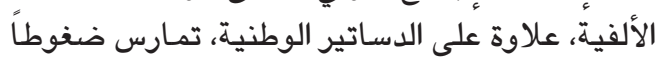

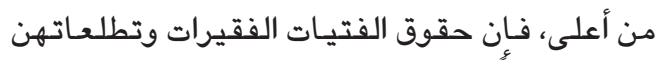
تشكل ضغطاً على مستوى القاعدة الشعبية العريضة.

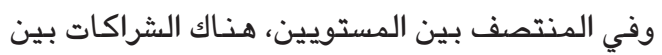

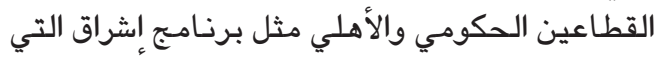

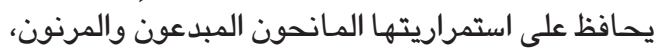

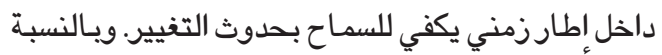

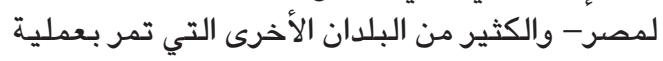

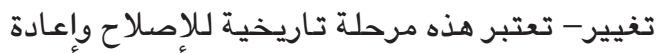

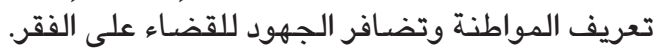

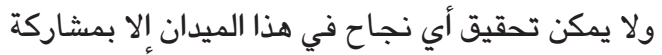
الفتيات اللاتي تخلفن عن الركب نجي.
وضـع فريق الموارد الخـاص بـاشـراق مسعايير

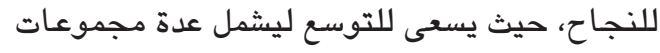

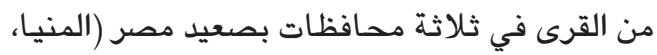

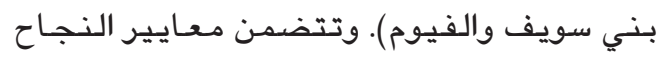

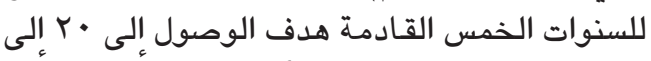

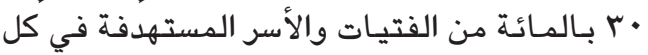

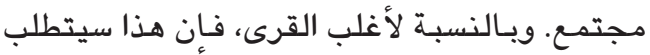

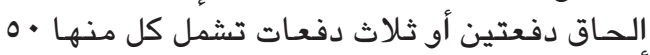

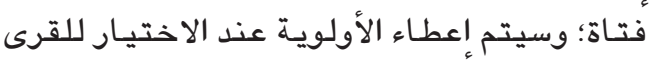

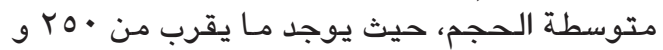

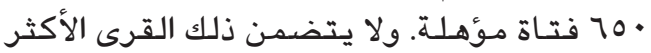

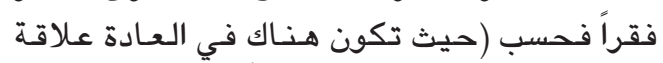

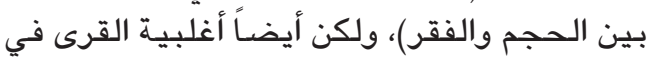

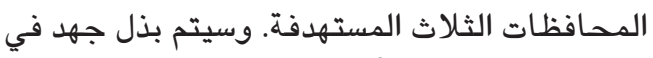

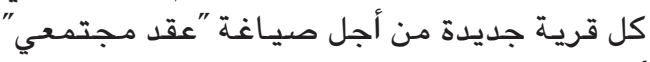

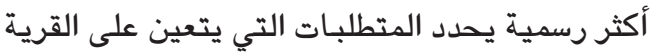

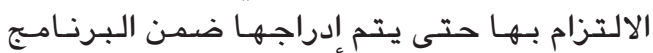

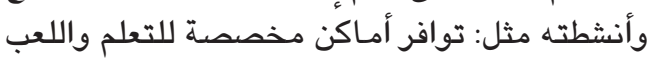

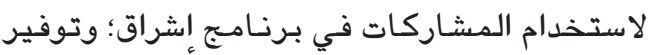

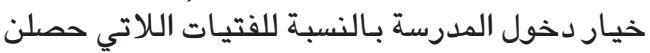

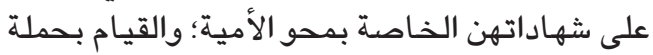
سنوية في القرية لضمان الضان أن تكون لجميع الأنيع الأطفال

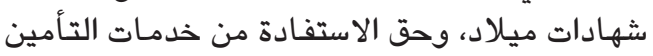

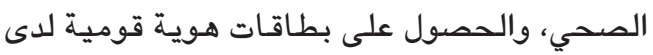

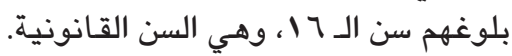

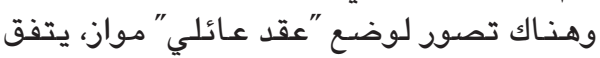

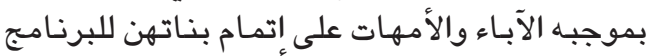

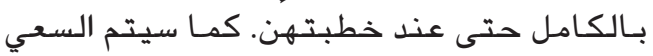

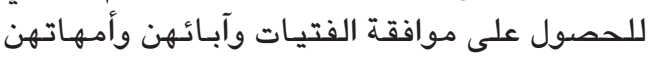

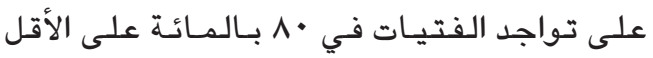

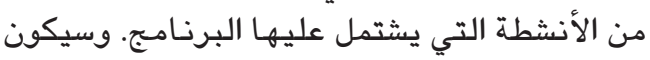

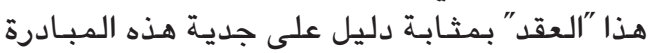

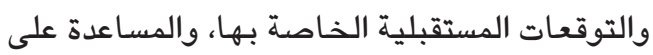

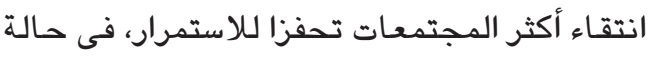

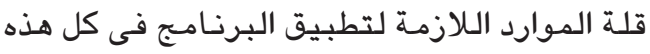

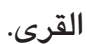




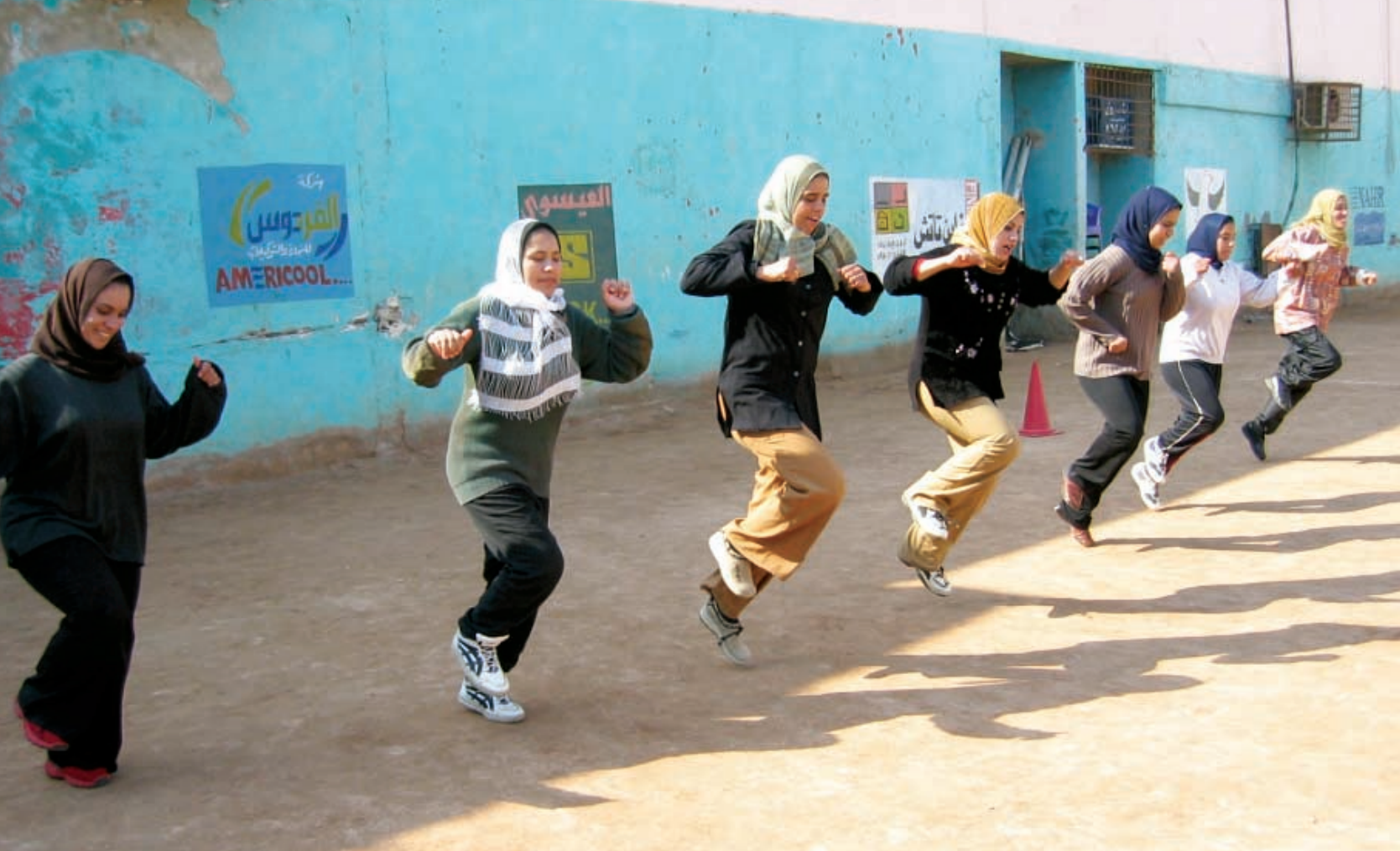

تدخل مصــر مرحسلة حيوية من الإصـاح وإعادة

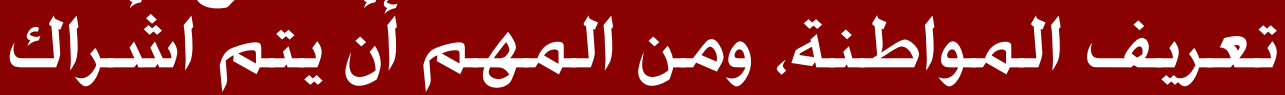

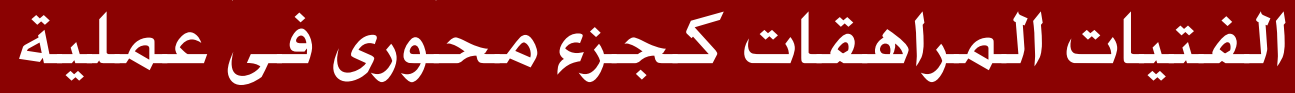
الإصـاحلاح الجـارية. 


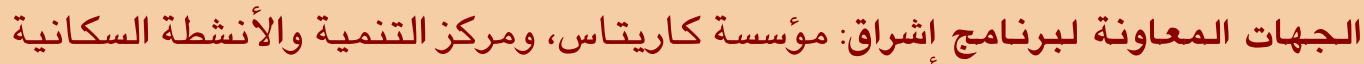

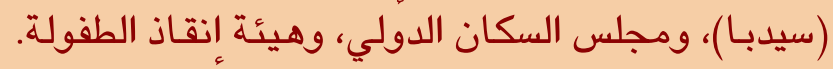

الشركاء الحكوميون: وزارة الشباب (المجلس الأعلى للشبـاب)، والمجلس القومي للطفولة والأمومة.

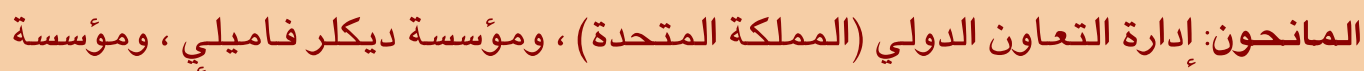

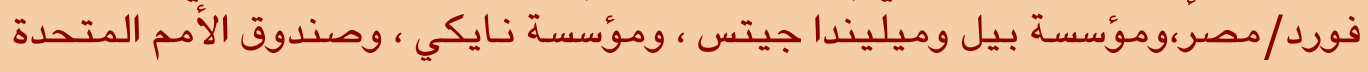

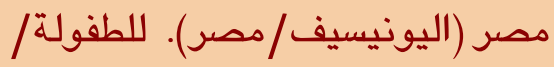

بقلم: مارثا بريدي، راجي أسعد، بـاربارا إبراهيم، عبير سالم، رانيا سالم، ونادية زيباني. جميح الصور الفوتوغرافية مهداة من نادية زيباني

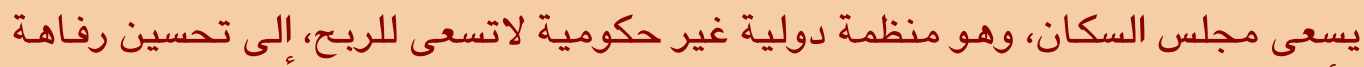

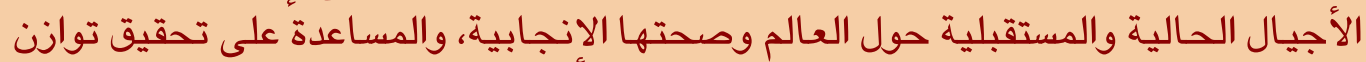
إنساني ومنصف ومستدام بين الأشخاص ولئس الفالم والموارد.

لمزيد من المعلومات حول برامج المجلس، يرجى زيارة الموقع الالكترونى WWw.popcouncil.org

حقوق الطبع محفوظة لمجلس السكان، 7 • • .

(C) مجلس السكان

\section{Population Council}

One Dag Hammarskjold Plaza, New York, NY 10017 www.popcouncil.org

www.popcouncil.org/pdfs/IshraqFullReport.pdf www.popcouncil.org/pdfs/IshraqReport.pdf 


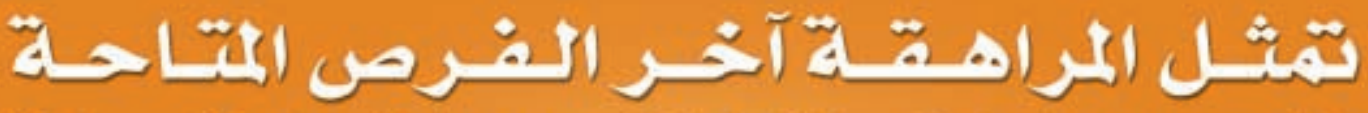

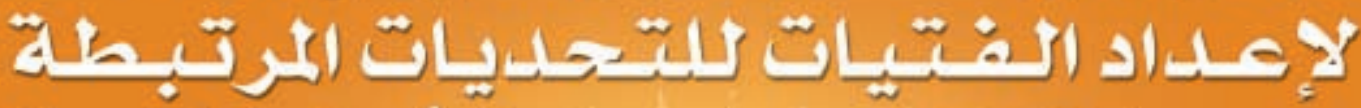

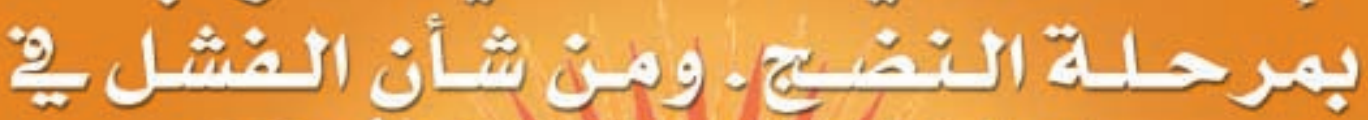

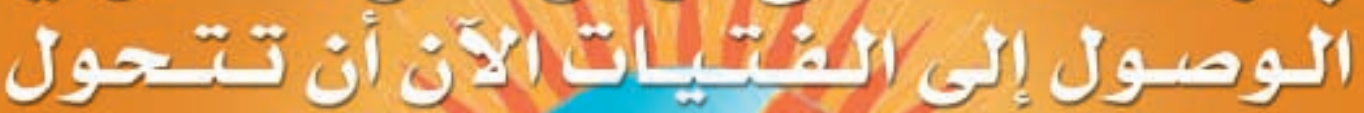

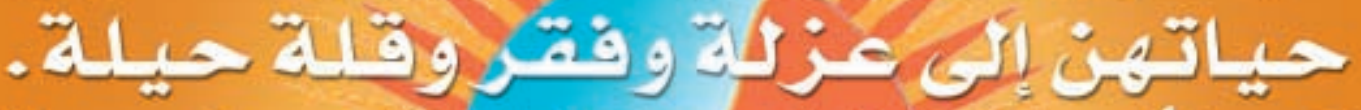

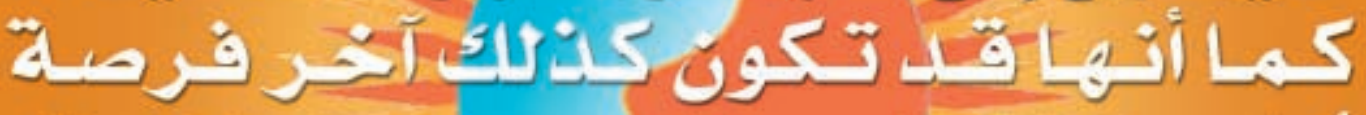

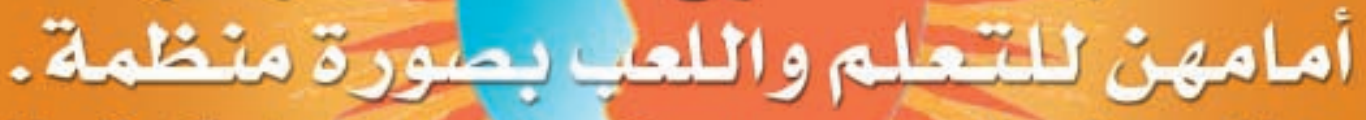
20 a

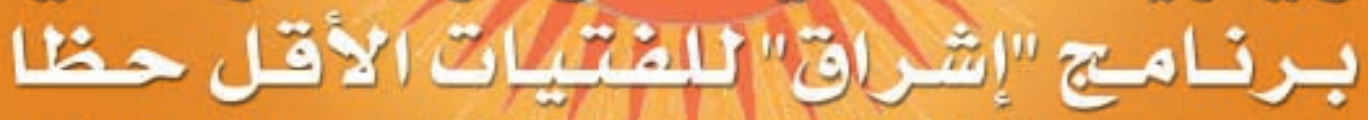

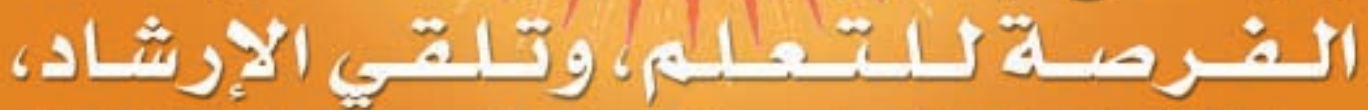

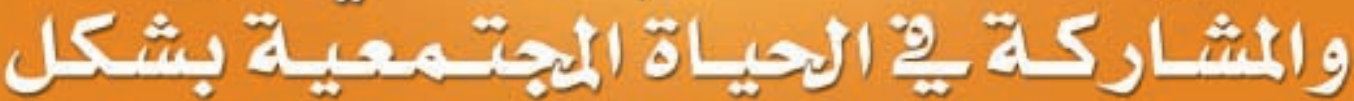
- مi

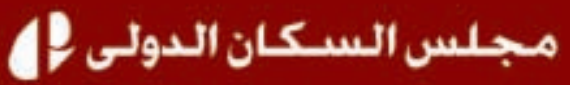

هه طريق مصر حلوان الزراعي، الهعادي، مصر ت: r.r) OY0-097 / Or0-097V / Or0-0970) فاكس: Y.r. (Y.0-097r) 